\title{
Some nematodes, including two new species, from freshwater fishes in the Sudan and Ethiopia
}

\author{
František Moravec and Tomáš Scholz
}

Institute of Parasitology, Biology Centre of the Czech Academy of Sciences, České Budějovice, Czech Republic

\begin{abstract}
Fourteen species (twelve adult and two larval) of nematodes belonging to the Ascaridoidea, Camallanoidea, Cosmocercoidea, Habronematoidea, Oxyuroidea, Seuratoidea and Trichinelloidea were collected from fishes in the Sudan (River Nile and Atbara Dam Lake), whereas only four species (one adult and three larval) of the Ascaridoidea, Camallanoidea, Dioctophymatoidea and Trichinelloideafrom fishes in Ethiopia (Lake Tana). The Sudanese material also contained two previously unknown species, Cucullanus mormyri sp. n. from Mormyrus caschive Linnaeus (type host), Mormyrus sp. and Marcusenius cyprinoides (Linnaeus) (all Mormyridae), and Procamallanus (Spirocamallanus) pseudospiralis sp. n. from Synodontis schall (Bloch et Schneider) (type host), S. frontosus Vaillant and S. nigrita Valenciennes (all Mochokidae), which are described based on light and scanning electron microscopical studies. Cucullanus baylisi Campana-Rouget, 1961, a little-known parasite of Synodontis spp., is redescribed in detail. A key to Procamallanus (Spirocamallanus) spp. from African inland fishes is provided. Falcaustra guiersi Vassiliadès, 1973 is considered a junior synonym of F. hexapapillata (Khalil, 1962). The findings represent several new host and geographical records. Cucullanus baylisi Lakshmi, 2000 (= a homonym to C. baylisi Campana-Rouget, 1961) is re-named as C. dubius nom. n. and is considered a species inquirenda.
\end{abstract}

Keywords: helminth parasites, taxonomy, new taxa, Osteichthyes, Africa

Freshwater bodies in Africa contain almost $25 \%$ of the world's 13,000 freshwater fish species (Lévêque et al. 2008), with a high degree of endemism at species and family levels. In contrast, the present knowledge of the parasite fauna of African fishes is fragmentary and incomplete, especially when compared with other continents, which makes it impossible to assess reliably their diversity, interrelations, distribution and potential effects on their fish hosts. The only comprehensive sources of data on fish parasites in Africa are the checklists of Khalil (1971) and Khalil and Polling (1997), the latter reporting 568 species of helminth parasites of African freshwater fishes, including 72 species of adult parasitic nematodes (Nematoda) in 27 genera and several nematode larvae, almost all unidentified to the species level, in seven genera. However, both checklists are out of date and do not provide reliable information on the current state of species diversity of these fish parasites.

In the last decade, an unprecedented amount of fish parasites has been collected as part of long-term collaborative effort of Czech research institutions in a close cooperation with African researchers and students. The new material made possible to conspicuously expand our knowledge of the parasite diversity in Africa, including that of nematodes (e.g. Koubková et al. 2008, 2010, Mašová et al. 2010, Kuchta et al. 2012). During short-term studies on the helminth parasites of fishes carried out by the junior author of this paper (T. S.) and his collaborators in the Sudan and Ethiopia in 2006 and 2008, a collection of parasitic nematodes was obtained. Since the fauna of nematode parasites of fishes in Africa still remains little known, results of the systematic evaluation of this material are presented herein.

\section{MATERIALS AND METHODS}

The present study was based on the examination of freshwater fishes collected in several localities in Ethiopia and the Sudan from March 2006 to November 2008 (see de Chambrier et al. 2007, 2008, Kuchta et al. 2012). Fish were dissected as soon as possible after their capture and parasites were isolated from the host intestine, rinsed in saline, fixed immediately in hot (almost boiling) 4\% neutral buffered formaldehyde solution (with pieces of several worms placed in $99 \%$ pure ethanol for future DNA analysis) and subsequently stored in 70\% ethanol.

For light microscopical examination (LM), the nematodes were cleared gradually in glycerine. Drawings were made with the aid of a Zeiss microscope drawing attachment. Specimens used for scanning electron microscopy (SEM) were post-fixed in 1\% osmium tetroxide (in phosphate buffer), dehydrated through a graded ethanol series, critical-point-dried and sputter-coated with gold; they were examined using a JEOL JSM-7401F scanning electron microscope at an accelerating voltage of $4 \mathrm{kV}$ (GB low mode). All measurements are in micrometres unless otherwise indicated. The names of fishes follow FishBase (Froese and Pauly 2017). 


\section{RESULTS}

Cosmocercoidea Railliet, 1916

Kathlaniidae Lane, 1914

Falcaustra hexapapillata (Khalil, 1962)

Figs. 1, 2

Syns. Spironoura hexapapillata Khalil, 1962; Falcaustra guiersi Vassiliadès, 1973 - new synonym

Description. Medium-sized, fusiform, whitish nematodes. Cuticle finely transversely striated. Lateral alae absent. Deirids well developed, rounded, situated at about mid-level of oesophagus (Figs. 1A, 2F). Oral aperture large, triangular, surrounded by 3 small lips, each bearing 2 cephalic papillae; pair of amphids present (Fig. 1B). Buccal cavity supported by flat cuticularised ring. Oesophagus consists of short, muscular pharyngeal portion, long corpus, inflated isthmus forming pre-bulb, and bulb (Fig. 1A). Nerve ring encircling oesophageal corpus at about $1 / 4$ of way along its length, excretory pore near level of junction of corpus and pre-bulb (Fig. 1A). Anterior end of intestine expanded. Tail of both sexes conical, sharply pointed.

Male (five specimens). Length of body $12.3-19.8 \mathrm{~mm}$, maximum width 558-966. Lips 41-54 long; width of cephalic end at level of lips 95-163. Length of entire oesophagus $2.4-2.6 \mathrm{~mm}$; length of pharynx $68-82$, of corpus 1.8-2.0 mm, of pre-bulb 177-258, of bulb 258-299; width of pharynx, corpus, pre-bulb and bulb 82-136, 109-150, 109-136 and 245-326, respectively. Nerve ring 462-530, deirids $1.3-1.6 \mathrm{~mm}$ and excretory pore $1.8-2.0 \mathrm{~mm}$ from anterior extremity. Posterior end of body curved ventrally. Caudal alae absent. Ventral precloacal sucker present, situated 3.4-6.5 mm from cloacal aperture; ventral side of body between cloaca and sucker with $\mathrm{ca}$ 102-108 pairs of oblique muscle bands (Fig. 1J).

Fourteen pairs of caudal papillae present, of which 6 subventral pairs are preanal, 1 adanal pair and 7 pairs (5 subventral and 2 lateral; phasmids represent posterior lateral pair) postanal (Figs. 1D,I,J, 2A-E). One additional unpaired median papilla present on anterior cloacal lip (Figs. 1D,I,J, 2C,E). Spicules approximately equal, alate, slightly curved, 1.6-1.9 mm long (Figs. 1H,J, 2A-E). Gubernaculum well developed, rod-like in lateral view and wedge-shaped in ventral view, 231-272 long (Fig. 1D,J). Tail 204-272 long (Figs. 1D,I,J, 2B-E).

Female (five ovigerous specimens). Length of body 18.7-22.8 mm, maximum width 0.99-1.16 mm. Lips 41 long; width of cephalic end at level of lips 122-150. Length of entire oesophagus 2.4-2.7 mm; length of pharynx 68-82, of corpus 1.8-2.1 mm, of pre-bulb 204-231, of bulb 286-313; width of pharynx, corpus, pre-bulb and bulb 95-109, 122-150, 136-163 and 313-394, respectively. Nerve ring 449-517, deirids $1.1-1.2 \mathrm{~mm}$ and excretory pore 1.9-2.2 $\mathrm{mm}$ from anterior extremity. Vulva postequatorial, situated $11.4-13.6 \mathrm{~mm}$ from anterior extremity (at $58-62 \%$ of body length); vagina muscular, narrow, directed anteriorly from vulva. Eggs numerous, oval, thin-walled, 102-126 × 72-105; content of eggs in uterus uncleaved (Fig. 1E,F) or cleaved into two blastomeres (Fig. 1G). Tail 748-1,006 long, bearing dorsolateral pair of large phasmids (Fig. 1C).

Host: Distichodus nefasch (Bonnatere) (Characiformes: Distichodidae).

Site of infection: Intestine.

L o cality: White Nile in Kostí, Sudan (collected 25 March 2006; host field number Sud109).

Prevalence: 1 fish infected/1 fish examined; 32 nematodes.

Deposition of voucher specimens: Helminthological Collection of the Institute of Parasitology, Biology Centre of the Czech Academy of Sciences, České Budějovice (IPCAS), Cat. No. N-1125.

Remarks. To date, ten species of Falcaustra Lane, 1914 have been described from fishes in Africa: F. guiersi Vassiliadès, 1973, F. hexapapillata (Khalil, 1962), F. petrei (Khalil, 1970), F. piscicola (von Linstow, 1907), F. similis Moravec et Van As, 2004, F. straeleni Campana-Rouget, 1961, F. sudanensis (Khalil, 1962), F. tchadi Vassiliadès et Troncy, 1973, F. therezieni Petter, 1979 and $F$. verbekei Campana-Rouget, 1961 (see Khalil and Polling 1997, Moravec and Van As 2004). Most of them are typically parasites of characiform, cypriniform and perciform fishes (although $F$. guiersi, $F$. straeleni and $F$. therezieni were occasionally also reported from catfishes), whereas $F$. similis is known only from siluriform hosts (Moravec and Van As, 2004, 2015a).

Only two of the above-mentioned species are reported to possess six pairs of preanal papillae (in contrast to three pairs in all other species): F. hexapapillata from Distichodus nefasch (syn. D. niloticus [Hasselquist]) in the Sudan and $F$. guiersi from $D$. rostratus Günther in Senegal (Khalil 1962, Vassiliadès 1973). The latter species was differentiated from the former one mainly by some details in the mouth structure (but both of these species were studied only by LM) and by the larger body and longer oesophagus and spicules (Vassiliadès 1973).

The present specimens are morphologically very similar to $F$. hexapapillata, but their body is more than twice as long as that reported for $F$. hexapapillata by Khalil (1962) (males 12.3-19.8 mm, gravid females 18.7-22.8 mm vs males $6.2-6.7 \mathrm{~mm}$, females 7.6-7.9 $\mathrm{mm}$ ) and the spicules are considerably longer (1.6-1.9 $\mathrm{mm}$ vs $1.2-1.3 \mathrm{~mm})$. By these measurements, they are closer to $F$. guiersi (body length of male and female $10 \mathrm{~mm}$ and $14.3 \mathrm{~mm}$, respectively; spicules $1.5 \mathrm{~mm}$ long - see Vassiliadès 1973). Since there are practically no other than biometrical differences between $F$. hexapapillata and $F$. guiersi and because the present specimens were collected from the same host species (D. nefasch) and the same locality (River Nile in Sudan) as $F$. hexapapillata, it is apparent that all these biometrical differences are within the intraspecific variability of one and the same species, $F$. hexapapillata, and that $F$. guiersi is its junior synonym.

The present SEM examination of $F$. hexapapillata, used in this species for the first time, revealed mainly the true 

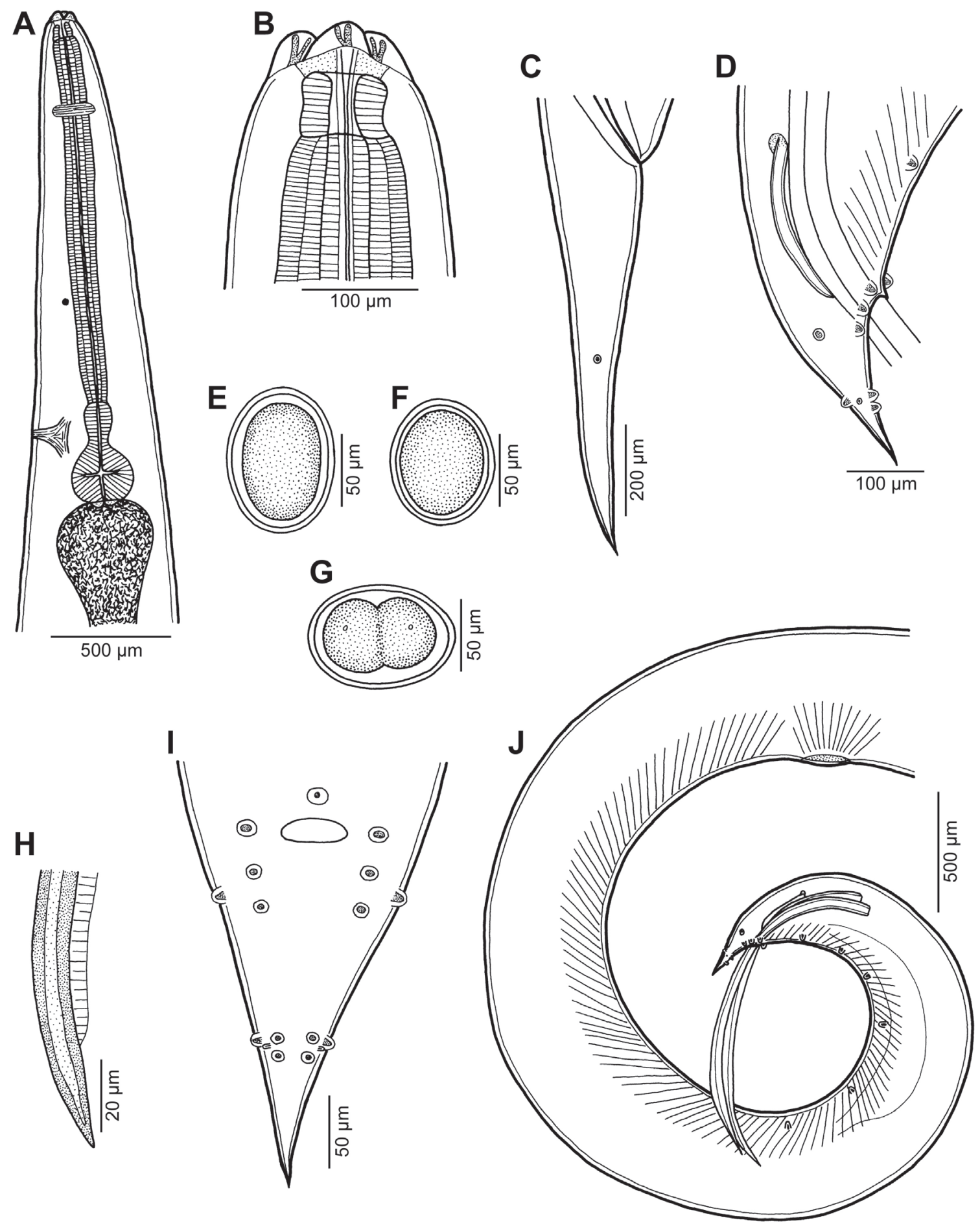

Fig. 1. Falcaustra hexapapillata (Khalil, 1962) from Distichodus nefasch (Bonnatere). A - anterior end of male, lateral view; B - cephalic end of male, lateral view; $\mathbf{C}$ - tail of female, lateral view; D - tail of male, lateral view; $\mathbf{E}-\mathbf{G}$ - eggs; $\mathbf{H}$ - distal end of spicule, lateral view; $\mathbf{I}$ - tail of male, ventral view; $\mathbf{J}$ - posterior end of male, lateral view.

structure of the cephalic end and the exact number and distribution of male caudal papillae.

Falcaustra similis Moravec et Van As, 2004

Ho st s: Synodontis frontosus Vaillant, S. nigrita Valenciennes, S. schall (Bloch et Schneider) and S. serratus Rüppell (all Siluriformes: Mochokidae).

Site of infection: Intestine.

L o calities: Blue Nile in Sennar (S. frontosus, S. serratus) (collected 22 and 23 November 2008; Sud410, Sud475b) and Atbara Dam Lake in Khashm el Girba (S. frontosus, S. nigrita, S. schall) (25 and 26 November 2008; Sud522b, Sud557, Sud558c, Sud559), both Sudan.

Prevalence and intensity: $S$. frontosus, Blue Nile: 1 fish infected/1 fish examined; 1 nematode. S. frontosus, Atbara Dam Lake: $1 / 4$; 1 . S. nigrita, Atbara Dam Lake: $2 / 3 ; 1$ and 6. S. schall, Atbara Dam Lake: $1 / 2$; 1 . S. serratus, Blue Nile: $1 / 1 ; 1$.

Deposition of voucher specimens: IPCAS N-819. 

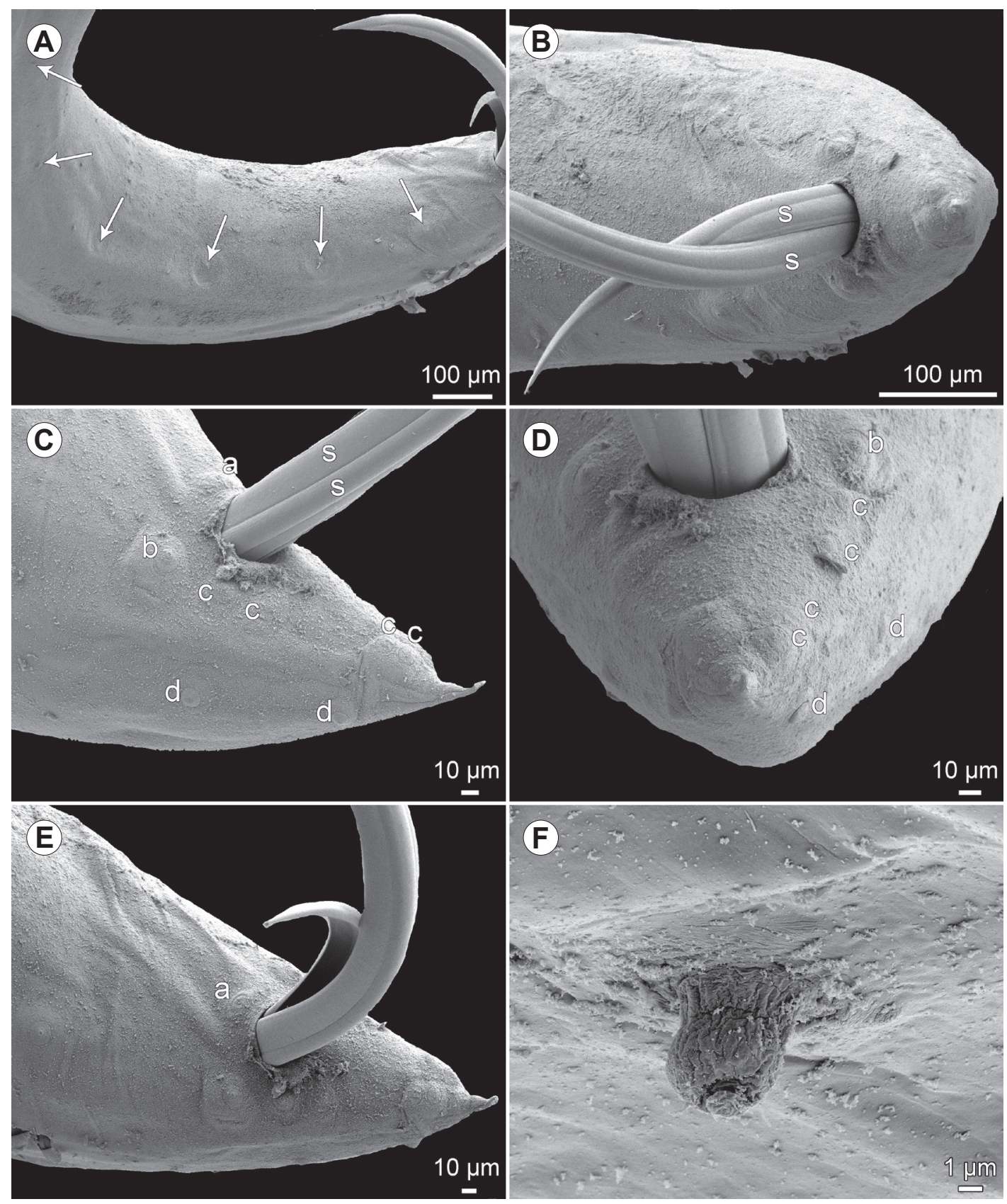

Fig. 2. Falcaustra hexapapillata (Khalil, 1962) from Distichodus nefasch (Bonnatere), scanning electron micrographs of male. A - precloacal region of body, sublateral view (arrows indicate preanal papillae); B - posterior end, ventral view; C, D - tail, lateral and ventral views, respectively; $\mathbf{E}$ - caudal end, subventral view; F - deirid. Abbreviations: a - unpaired median preanal papilla; b - adanal papilla; $\mathrm{c}$ - subventral postanal papilla; $\mathrm{d}$ - lateral postanal papilla; $\mathrm{s}$ - spicule.

Remarks. The present nematodes are in full agreement with the descriptions of $F$. similis provided by Moravec and Van As $(2004,2015 a)$. This species is a specific parasite of African catfishes (see above), previously reported from Synodontis nigromaculatus Boulenger (type host), S. vanderwaali Skelton et White (both Mochokidae) and Schilbe intermedius Rüppell (Schilbeidae) in Botswana (Moravec and Van As 2004, 2015a). The findings of F. similis from $S$. frontosus, $S$. nigrita, S. schall and S. serratus in the Sudan represent new host and geographical records.

Falcaustra similis can be easily distinguished from the foregoing species $F$. hexapapillata by the presence of only three pairs of preanal papillae and by much shorter spicules not exceeding $530 \mu \mathrm{m}$.

Seuratoidea Hall, 1916

\section{Cucullanidae Cobbold, 1864}

Cucullanus barbi Baylis, 1923

Description of male (one specimen). Length of body $11.5 \mathrm{~mm}$, maximum width 435 . Length of entire oesophagus $1.4 \mathrm{~mm}$, representing $12 \%$ of whole body length; 
length of oesophastome 231, its width 190; maximum width of posterior part of oesophagus 177. Distance of nerve ring from anterior extremity 476, representing 33\% of oesophageal length. Deirids and excretory pore 762 and 639, respectively, from anterior end of body. Posterior end of body curves ventrally. Cloacal region not elevated. Large median papilla-like formation present anterior to cloacal opening.

Spicules equal, $1.0 \mathrm{~mm}$ long, representing $9 \%$ of body length. Gubernaculum small, well sclerotised, 93 long. Ventral sucker well developed, located at 1,006 anterior to cloacal opening. Genital papillae 10 pairs: 5 pairs of subventral preanal papillae, 1 pair of subventral adanal papillae and 4 pairs of papillae, of which 3 subventral and 1 dorsolateral. First pair of subventral postanal papillae just posterior to cloacal opening, second and third pairs of subventral postanals in middle region of tail; dorsolateral pair of postanals at level of last pair of subventrals. Length of tail 286.

H o s t: Barbus bynni (Forsskål) (Cypriniformes: Cyprinidae). Site of infection: Intestine.

L o c a lity: White Nile in Kostí and Blue Nile in Sennar, Sudan (collected 19 and 22 November 2008; Sud311, Sud416).

Prevalence and intensity: 2 fish infected/ 2 fish examined; 1 nematode per fish.

Deposition of voucher specimen: IPCAS N-20.

Remarks. Only a single damaged specimen was available to study, whose identification is supported by the fact that it was collected from the type host species in the type locality. This species was inadequately described by Baylis (1923a) from Barbus bynni in the Sudan (Khartoum) and later it was redescribed by Moravec (1974) from the same host species (B. bynni) and B. perince Rüppell from Egypt (Nile). Subsequently, C. barbi was reported from B. bynni in Egypt by Amin (1978) and El-Naffar et al. (1983).

\section{Cucullanus baylisi Campana-Rouget, $1961 \quad$ Figs. 3, 4}

Description. Medium-sized nematodes. Body whitish, elongate, with slightly transversely striated cuticle. Lateral alae absent. Cephalic end somewhat asymmetrical in lateral view. Oral aperture dorsoventrally elongate, surrounded by raised narrow membraneous ala (collarette) supported by row of $c a 60$ minute basal teeth (Fig. 4G). Four submedian cephalic papillae and pair of lateral amphids present (Figs. 3C, 4A,B). Oesophagus muscular, expanded at anterior end to form bulbous pseudobuccal capsule (oesophastome); posterior part of oesophagus also expanded, somewhat narrower than oesophastome (Fig. 3A,B,D). Oesophagus opens into intestine through large valve. Nerve ring encircles oesophagus at distance representing 39-44\% of oesophageal length. Deirids small, situated posterior to midway between nerve-ring and posterior end of oesophagus (Figs. 3A,B,D, 4H). Postdeirids not found. Excretory pore in region of oesophago-intestinal junction (Fig. 3A,D). Tail of both sexes conical, sharply pointed at tip.

Male (nine specimens from Synodontis sp.). Length of body 5.9-10.8 mm, maximum width 268-490; width at level of oesophastome 163-245, at middle of oesophagus 204-299. Length of entire oesophagus 680-952, representing $8-12 \%$ of whole body length; length of oesophastome 204-272, its width 150-218; minimum width of oesophagus 68-95; maximum width of posterior part of oesophagus 109-177. Distance of nerve ring from anterior extremity 299-381, representing 39-44\% of oesophageal length. Deirids and excretory pore 558-925 and 721-993, respectively, from anterior end of body. Posterior end of body curved ventrally. Cloacal region not elevated. Large median papilla-like formation present anterior to cloacal opening (Figs. 3G,I,J, 4C-E).

Spicules equal, 530-639 long, with rounded posterior ends (Fig. 3G,H), representing 5-9\% of body length. Gubernaculum well sclerotised, small, rod-like in lateral view and somewhat V-shaped in ventral view, 109-150 long (Fig. 3G,I,J,K). Ventral sucker and ventral precloacal oblique muscle bands absent (Figs. 3G, 4C). Genital papillae 9 pairs: 5 pairs of subventral preanal papillae and 4 pairs (3 subventral and 1 lateral) of postanal papillae. First pair of subventral postanal papillae just posterior to cloacal opening, second and third pairs of subventral postanals in middle region of tail; lateral pair of postanals at level of second pair of subventrals (Figs. 3G,I,J, 4C-E). Length of tail including terminal spike 231-286 (Figs. 3G,I,J, 4C-E).

Female (three specimens with mature eggs; measurements of four specimens with immature eggs in parentheses and those of one lacking eggs in brackets; all from Synodontis sp.). Length of body 10.4-16.8 mm (6.8-8.2 mm) [5.8 mm], maximum width 367-612 (258-354) [218]; width at level of oesophastome 218-272 (122-204) [177], at middle of oesophagus 245-367 (163-258) [204]. Length of entire oesophagus 870-1,006 (748-870) [734], representing 6-8\% (9-12\%) [13\%] of whole body length; length of oesophastome 286 (231-245) [190], its width 204-231 (163-204) [150]; minimum width of oesophagus 95-109 (68-95) [68]; maximum width of posterior part of oesophagus 163-204 (122-150) [95]. Distance of nerve ring from anterior extremity 354-422 (313-367) [299], representing 41-42\% (39-44\%) [41\%] of oesophageal length. Deirids and excretory pore 762-952 (639-775) [653] and 898-1,428 (707-775) [653], respectively, from anterior end of body.

Vulva postequatorial, $6.1-9.8 \mathrm{~mm}(4.0-4.7 \mathrm{~mm})$ [3.4 mm] from anterior extremity, at 58-59\% (57-60\%) [58\%] of body length; vulval lips not elevated or slightly elevated. Vagina directed anteriorly from vulva. Uteri opposed, containing numerous mature eggs (few immature eggs) [no eggs]; in all specimens, coils of anterior ovary reach anteriorly to short distance posterior to end of oesophagus, those of posterior ovary extend posteriorly to level of rectum. Eggs oval, thin-walled, with uncleaved content; surface of eggs with fine granular sculpture (Fig. 3F). Size of fully developed eggs 84-90 × 54-66. Length of tail 326-340 (258-286) [286]; pair of small lateral papilla-like phasmids present near posterior end of tail (Figs. 3E, 4F).

H o s t s : Synodontis schall (Bloch et Schneider) and Synodontis 

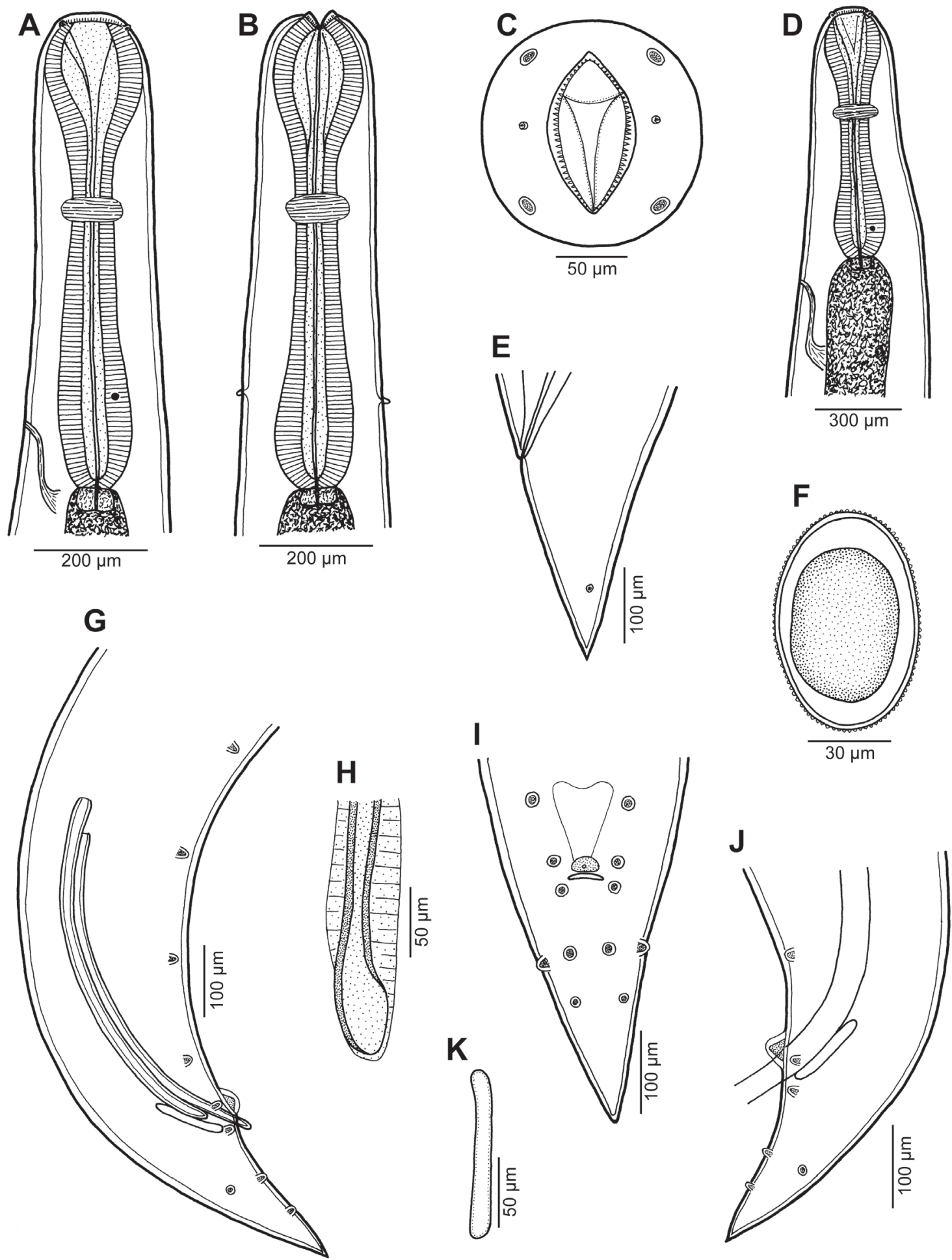

Fig. 3. Cucullanus baylisi Campana-Rouget, 1961 from Synodontis schall (Bloch et Schneider). A, B - anterior end of male, lateral and dorsoventral views, respectively; $\mathbf{C}$ - cephalic end, apical view; $\mathbf{D}$ - anterior end of largest gravid female, lateral view; $\mathbf{E}$ - tail of gravid female, lateral view; $\mathbf{F}$ - egg; $\mathbf{G}$ - posterior end of male, lateral view; $\mathbf{H}$ - distal end of spicule, lateral view; $\mathbf{I}, \mathbf{J}$ - tail of male, ventral and lateral views, respectively; $\mathbf{K}$ - gubernaculum, lateral view.

sp. (Siluriformes: Synodontidae).

Site of infection: Intestine.

L o c a li ty: White Nile in Kostí (Synodontis sp.) and Blue Nile in Sennar (S. schall), both Sudan (collected 25 and 26 March 2006 and 21 November 2008, respectively; Sud097, Sud104, Sud105, Sud125, Sud126, Sud130, Sud131, Sud134, Sud137, Sud372b).
Prevalence and intensity: Synodontis sp., White Nile: 9 fish infected/9 fish examined; 1-8 nematodes per fish. S. schall, Blue Nile: $1 / 1 ; 2$.

Deposition of voucher specimens: IPCAS N-1119.

Remarks. Only two damaged juvenile females of $\mathrm{Cu}$ cullanus Müller, 1777 were obtained from S. schall (the 

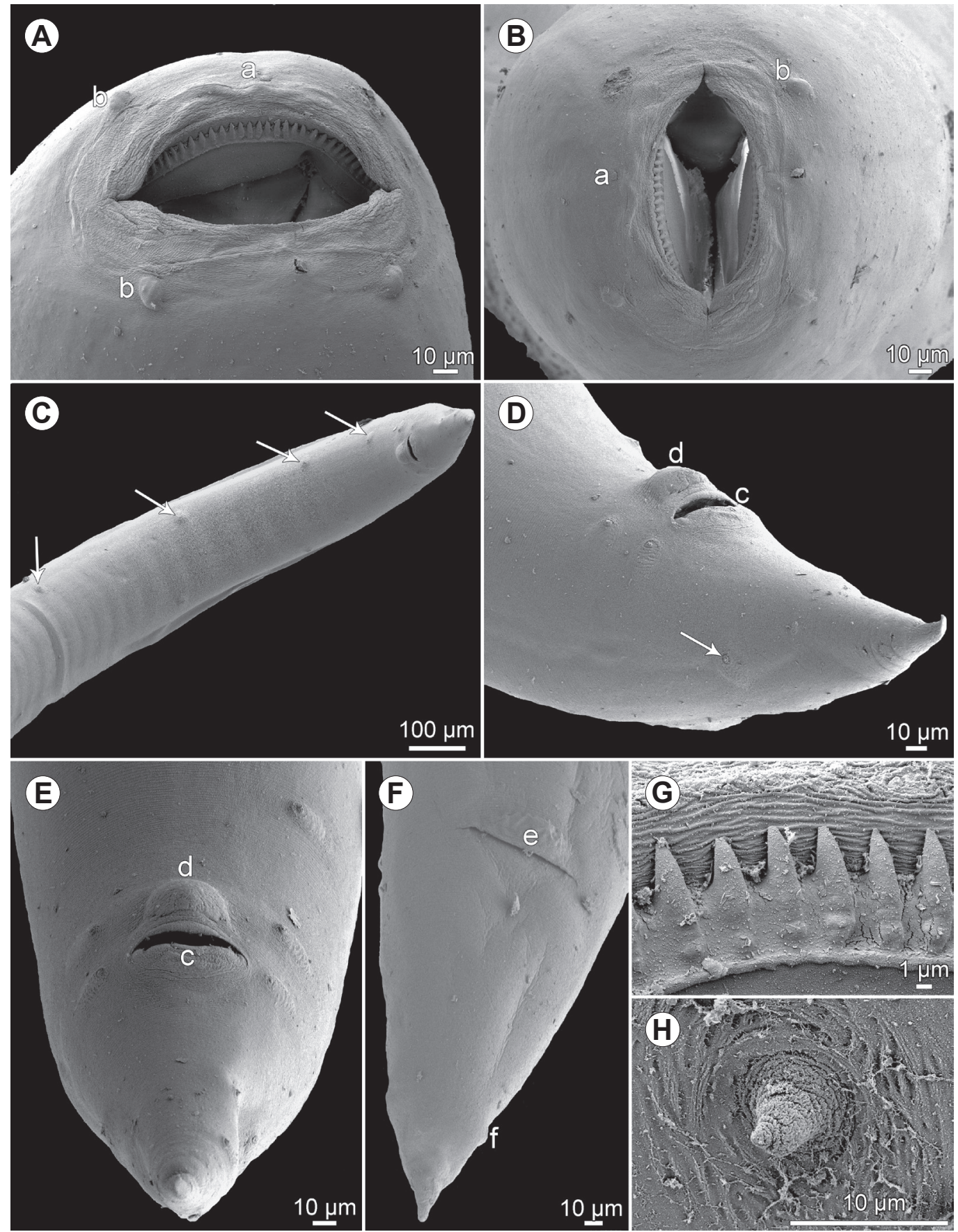

Fig. 4. Cucullanus baylisi Campana-Rouget, 1961 from Synodontis schall (Bloch et Schneider), scanning electron micrographs. A, B - cephalic end, lateral and apical views, respectively; C - posterior end of male, ventral view (arrows indicate preanal papillae); D - tail of male, lateral view (arrow indicates lateral postanal papilla); $\mathbf{E}$ - same, ventral view; $\mathbf{F}$ - tail of female, ventral view; $\mathbf{G}$ - detail of circumoral denticles; $\mathbf{H}$ - deirid. Abbreviations: a - amphid; b - cephalic papilla; c - cloacal aperture; $\mathrm{d}$ - unpaired median preanal papilla; e - anus; $\mathrm{f}$ - phasmid.

type host of $C$. baylisi), so that their species identification is mainly based on the host species, in addition to some morphological features. However, males and females of congeneric nematodes obtained from Synodontis sp. are more or less in agreement with the original description of C. baylisi, so that there is no doubt that they also belong to this species. Campana-Rouget (1961) described C. baylisi from $S$. schall in the Democratic Republic of the Congo and she assigned to this species also the congeneric female specimen erroneously reported by Baylis (1923a) as
C. clarotis Baylis, 1923 from S. schall in the Sudan (River Nile, Khartoum).

The present study of C. baylisi based on LM and SEM examinations (the latter used in this species for the first time) made it possible to redescribe this species in detail, especially as to the distribution of otherwise poorly visible male genital papillae. In contrast to present data, Campana-Rouget (1961) reported an additional pair of poorly visible lateral papillae at the level of the cloacal aperture, but the SEM examination did not confirm the presence of 
such papillae. The small subunit rRNA gene of C. baylisi of this Sudanense material (from Synodontis sp.) was sequenced by Černotíková et al. (2011) (GenBank Acc. No. JF803935).

Bharatha Lakshmi (2000) inadequately described a new species of Cucullanus, C. baylisi Lakhsmi, 2000, from the intestine of the marine catfish Netuma thalassina (Rüppel) (Ariidae, Siluriformes) in the Bay of Bengal, off Andhra Pradesh, India. However, the proposed name is a junior homonym to C. baylisi Campana-Rouget, 1961, a parasite of freshwater fishes in Africa. Therefore, we propose to rename the Indian species as Cucullanus dubius nom. $\mathbf{n}$. due to its poor and questionable description and to designate it as a species inquirenda. It is worth mentioning that, in addition to $C$. dubius, five other, mostly inadequately described species of Cucullanus (C. arii Yamaguti, 1955, C. armatus Yamaguti, 1954, C. goasthanensis Bharathalakshmi et Sudha, 2000, C. olivaceus Akram, 1976 and C. tachysurus Akram, 1976), are reported from the same host species ( $N$. thalassina) in the region of the Indian Ocean (Parukhin 1989, Akram 1994, Petter and Sey 1997, Bharathalakshmi and Sudha 2000).

\section{Cucullanus mormyri sp. n.}

Figs. 5, 6

ZooBank number for species:

urn:1sid:zoobank.org:act:0436EBAD-FD45-4AB0-9F24-58EAE0A8D974

Description. Medium-sized nematodes. Body whitish, elongate, with slightly transversely striated cuticle. Lateral alae absent. Cephalic end somewhat asymmetrical in lateral view. Oral aperture dorsoventrally elongate, surrounded by raised narrow membraneous ala (collarette) supported by row of $c a 110$ minute basal teeth. Four submedian cephalic papillae and pair of lateral amphids present (Figs. 5D,F, 6A-C). Oesophagus muscular, expanded at anterior end to form bulbous pseudobuccal capsule (oesophastome); posterior part of oesophagus also expanded, somewhat narrower than oesophastome (Fig. 5A-C). Oesophagus opens into intestine through large valve. Nerve ring encircles oesophagus at distance representing 37-45\% of oesophageal length. Deirids small, situated near midway between nerve ring and posterior end of oesophagus (Figs. 5A-C, 6D). Postdeirids not found. Excretory pore far posterior to oesophago-intestinal junction (Fig. 5A). Tail of both sexes conical, with small, pointed cuticular spike at tip (Figs. 5E, G-I, 6E-G).

Male (three specimens from $M$. caschive and one from Mormyrops sp.; measurements of holotype in parentheses). Length of body $7.1-8.7 \mathrm{~mm}(8.6 \mathrm{~mm})$, maximum width 258-286 (286); width at level of oesophastome 190-218 (218), at middle of oesophagus 163-190 (190). Length of entire oesophagus 870-966 (952), representing 11-12\% (11\%) of whole body length; length of oesophastome 204-218 (218), its width 177-190 (190); minimum width of oesophagus 68-82 (68); maximum width of posterior part of oesophagus 136-163 (163). Distance of nerve ring from anterior extremity 340-381 (381), representing
$37-41 \%(40 \%)$ of oesophageal length. Deirids and excretory pore $612-680$ (666) and $1.6-1.8 \mathrm{~mm}(1.6 \mathrm{~mm})$, respectively, from anterior end of body. Posterior end of body curves ventrally. Cloacal region not elevated. Large median papilla-like formation present anterior to cloacal opening (Figs. 5G-I, 6E-G).

Spicules equal, 714-810 (726) long, with rounded posterior ends (Fig. 5G), representing 9-10\% (9\%) of body length. Gubernaculum small, well sclerotised, 42-48 (45) long (Fig. 5G-J). Ventral sucker and ventral precloacal oblique muscle bands absent (Figs. 5G, 6G). Genital papillae 10 pairs: 5 pairs of subventral preanal papillae, 1 pair of subventral adanal papillae and 4 pairs of postanal papillae, of which 3 pairs subventral and 1 pair dorsolateral. First pair of subventral postanal papillae just posterior to cloacal opening, second and third pairs of subventral postanals in middle region of tail; dorsolateral pair of postanals at level of last pair of subventrals. Phasmids small, lateral, slightly posterior to level of second pair of subventral postanal papillae (Figs. 5G-I, 6E-G). Length of tail including terminal spike 189-273 (273); length of spike 6 (6).

Female (one gravid specimen, allotype, from Mormyrus sp.). Length of body $8.0 \mathrm{~mm}$, maximum width 286; width at level of oesophastome 218 , at middle of oesophagus 177. Length of entire oesophagus 911 , representing $11 \%$ of whole body length; length of oesophastome 245 , its width 177; minimum width of oesophagus 82 ; maximum width of posterior part of oesophagus 150. Distance of nerve ring from anterior extremity 408, representing $45 \%$ of oesophageal length. Deirids and excretory pore 639 and 1,945, respectively, from anterior end of body. Vulva postequatorial, $5.0 \mathrm{~mm}$ from anterior extremity, at $62 \%$ of body length; vulval lips not elevated. Vagina directed anteriorly from vulva. Uteri opposed, containing numerous eggs; coils of anterior ovary reach anteriorly to short distance posterior to end of oesophagus, those of posterior ovary extend posteriorly to level of rectum. Eggs oval-shaped, thin-walled, size 75-84 × 48-57, with uncleaved content (Fig. 5K); surface of eggs with fine sculpture. Length of tail including terminal spike 207; length of spike 6; pair of small lateral papilla-like phasmids present near mid-length of tail (Fig. 5E).

Type host: Mormyrus caschive Linnaeus (Osteoglossiformes: Mormyridae) (3 nematode males).

Other hosts: Mormyrus sp. (1 nematode male and 1 female) and Marcusenius cyprinoides (Linnaeus) (1 nematode juvenile male) (both Mormyridae).

Site of infection: Intestine.

Type locality: White Nile in Kostí, Sudan (collected 27 March 2006 and 16 and 19 November 2008; Sud143, Sud220b, Sud325b).

Prevalence and intensity: $M$. caschive: 1 fish infected/1 fish examined; 4 nematodes. Mormyrus sp.: 1/1; 2. M. cyprinoides: $1 / 1 ; 2$.

Deposition of type specimens: Holotype, allotype and 3 paratypes, IPCAS N-1120.

Etymology: The specific name of this nematode relates to the genitive form of the generic name of the host. 

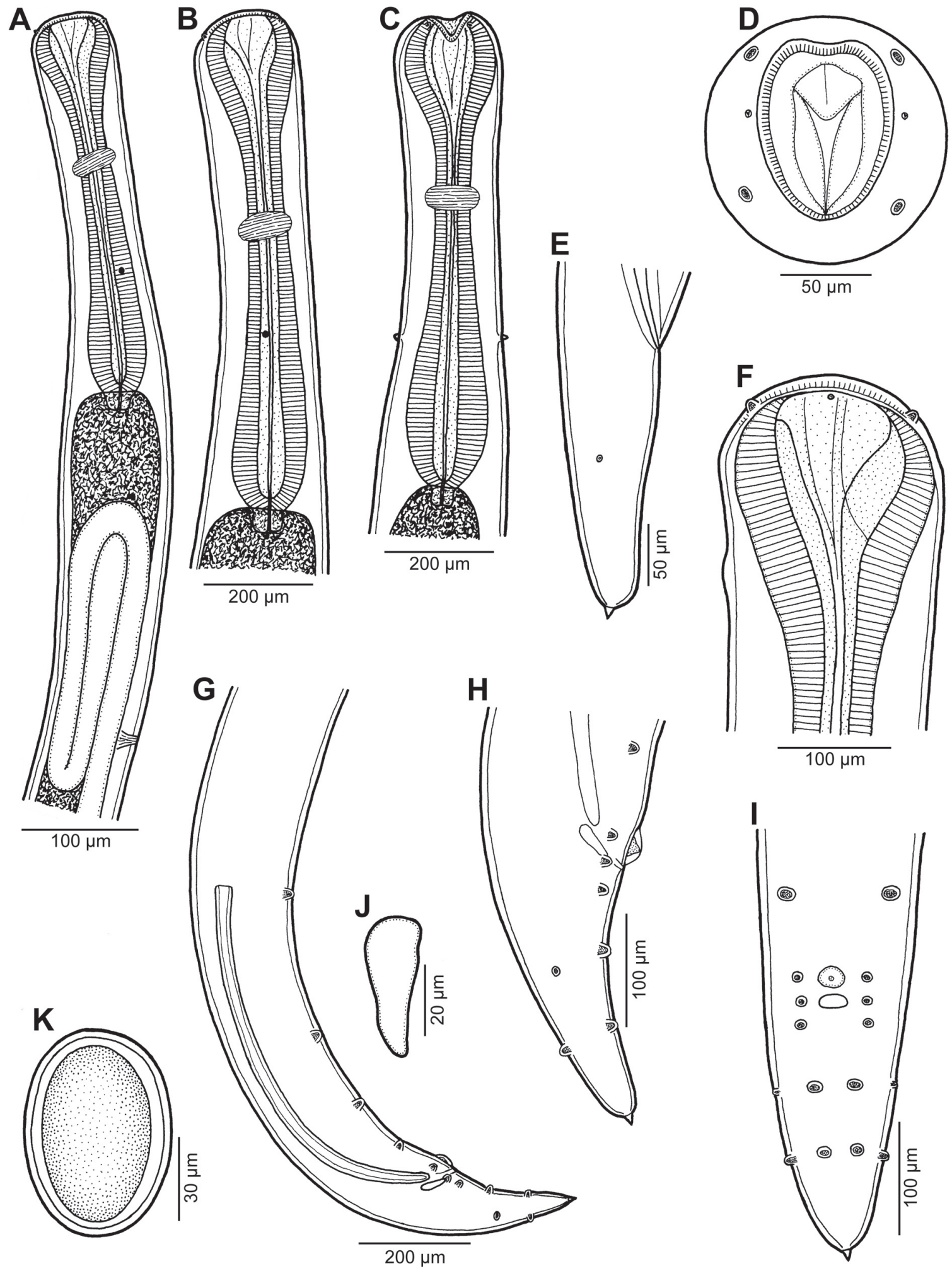

Fig. 5. Cucullanus mormyri sp. n. from Mormyrus spp. A - anterior part of male body, lateral view; $\mathbf{B}, \mathbf{C}$ - anterior end of male, lateral and dorsoventral views, respectively; D - cephalic end, apical view; $\mathbf{E}$ - tail of female, lateral view; $\mathbf{F}$ - pseudobuccal capsule of female, lateral view; $\mathbf{G}$ - posterior end of male, lateral view; H, I - tail of male, lateral and ventral views, respectively; $\mathbf{J}-$ gubernaculum, lateral view; K - egg. (A-D, G-I - holotype from M. caschive Linnaeus; E,F,K - allotype from Mormyrus sp.)

Remarks. To date, the following five species of $\mathrm{Cuc}$ ullanus were, mostly inadequately, described from freshwater and brackish-water anguilliform, cypriniform and mugiliform fishes in Africa: C. barbi Baylis, 1923, C. baylisi, C. clarotis, C. djilorensis Ndew, Diouf, Bâ et Morand,
2014 and C. egyptae Abdel-Ghaffar, Bashtar, Abdel-Gaber, Morsy, Mehlhorn, Al Quraishy et Mohammed, 2014 (see Baylis 1923a, Campana-Rouget 1961, Abdel-Ghaffar et al. 2014, Ndew et al. 2014). Cucullanus mormyri sp. n. can be easily distinguished from C. barbi, C. baylisi, C. clarotis 

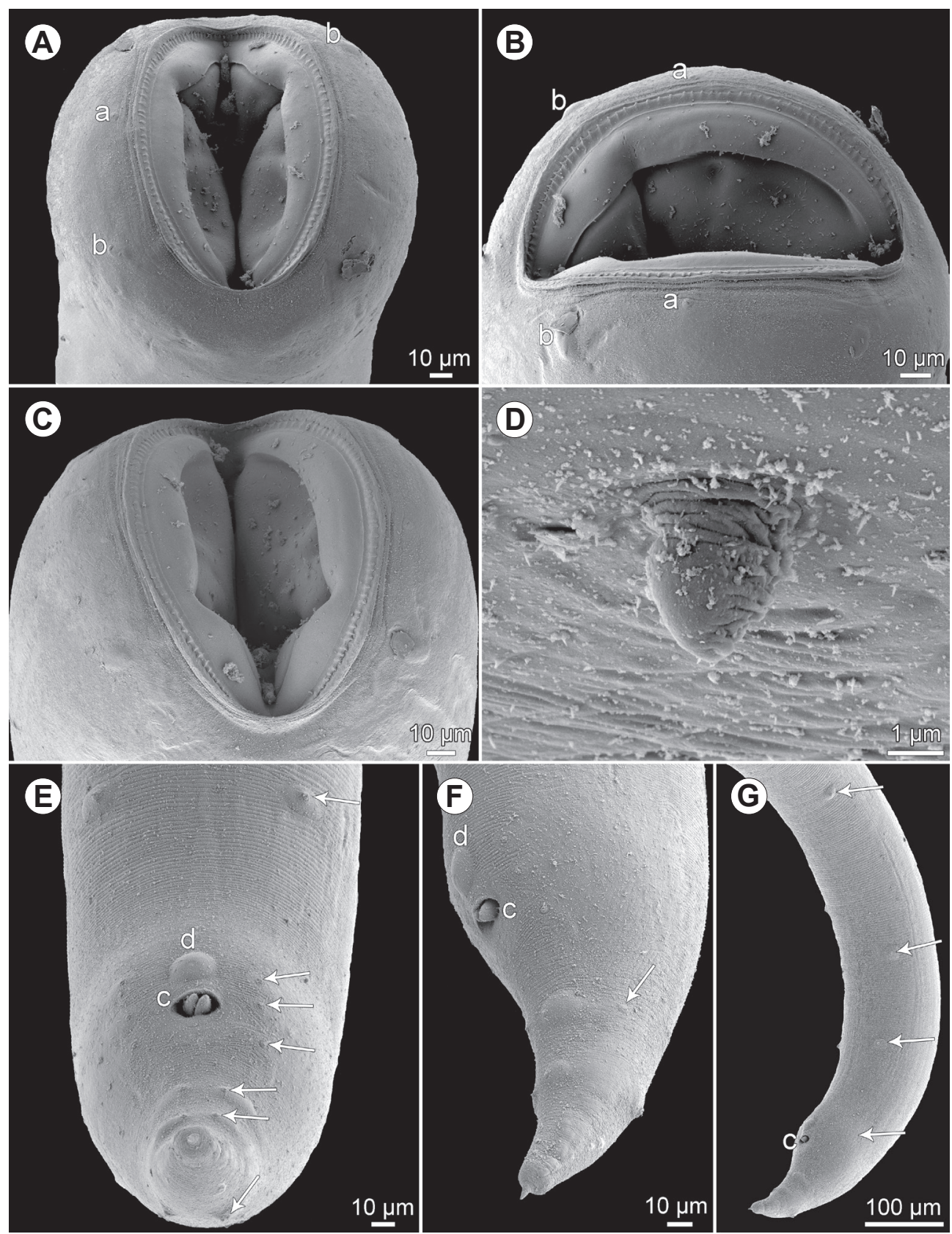

Fig. 6. Cucullanus mormyri sp. n. from Mormyrus caschive Linnaeus, scanning electron micrographs of male paratypes. A, B - cephalic end, apical and lateral views, respectively; $\mathbf{C}$ - same (another specimen), subdorsal view; D - deirid; $\mathbf{E}$ - tail, ventral view (arrows indicate subventral and subdorsal papillae); $\mathbf{F}$ - same, lateral view (arrow indicates phasmid); $\mathbf{G}$ - posterior end of body, lateral view (arrows indicate subventral preanal papillae). Abbreviations: a - amphid; b-submedian cephalic papilla; $\mathrm{c}$ - cloacal aperture; $\mathrm{d}$ - median precloacal papilla-like formation.

and $C$. djilorensis by the location of the excretory pore (at a long distance posterior to the end of the oesophagus $v s$ at the level of the oesophagus or just posterior to it) and by the arrangement of caudal papillae; from $C$. barbi also by longer spicules $(714-810 \mu \mathrm{m} v s \quad 400-639 \mu \mathrm{m})$ and from C. djilorensis also by the absence of a ventral precloacal sucker. The excretory pore of C. egyptae was not described, but this species differs from C. mormyri in the presence of a ventral precloacal sucker, absence of a median precloacal papilla-like formation and in having shorter spicules (590-650 $\mu \mathrm{m}$ vs 714-810 $\mu \mathrm{m}$ long). Cucullanus mormyri also differs from the above-mentioned African congeners in the order of the fish hosts (Osteoglossiformes vs Cypriniformes, Mugiliformes or Siluriformes).

\section{Oxyuroidea Cobbold, 1864}

Pharyngodonidae Travassos, 1919

Cithariniella khalili Petter, Vassiliadès et Troncy, 1972

Syn. Cithariniella gonzalezi Van Waerebeke, Chabaud, Bain et Georges, 1988 
Ho sts: Synodontis membranaceus (Geoffroy Saint-Hilaire) and S. serratus Rüppell (both Siluriformes: Mochokidae).

Site of infection: Intestine.

L o calities: White Nile River in Kostí and Blue Nile in Sennar, Sudan (collected 16 and 22 November, 2008, respectively; Sud229b, Sud410).

Prevalence and intensity: $S$. membranaceus, White Nile River: 1 fish infected/1 fish examined; 4 nematodes. Blue S. serratus, Nile River: $1 / 3 ; 9$.

Deposition of voucher specimens: IPCAS N-906.

Remarks. Only damaged female nematodes were available. Since the interspecific differences of Cithariniella spp. are mainly found in males (Koubková et al. 2010, Moravec and Van As 2015a), the identification of the present specimens is principally based on the genus of the definitive host. According to Moravec and Van As (2015a), C. khalili is the only species of this genus parasitising Synodontis spp. in Africa. With respect to the paper of Moravec and Van As (2015a), all previous records of C. citharini Khalil, 1964 from Synodontis spp. in Egypt concerned in fact $C$. khalili. The finding of $C$. khalili from $S$. serratus in the Sudan represents new host and geographical records.

Ascaridoidea Railliet et Henry, 1915

Anisakidae Railliet et Henry, 1912

Multicaecum heterotis Petter, Vassiliadès et Marchand, 1979

Host: Heterotis niloticus (Cuvier) (Osteoglossiformes: Arapaimidae).

Site of infection: Intestine.

Localities: River Nile in Khartoum (collected 21 March 2006; Sud017, Sud019) and White Nile in Kostí (27 March 2006; Sud145, Sud146, Sud147), both Sudan.

Prevalence and intensity: Khartoum: 2 fish infected/2 fish examined; 3 and 4 nematodes. Kostí: $3 / 3 ; 1-2$.

Deposition of voucher specimen: IPCAS N-947.

Remarks. Specimens of $M$. heterotis of this material have already been described in detail by Mašová et al. (2010), who also provided its molecular data. Now this nematode parasite is known from its type- and only known host species in Senegal, Nigeria and the Sudan (Petter et al. 1979, Akinsanya et al. 2007, Mašová et al. 2010).

Contracaecum sp. third-stage larva Type 1 of Moravec et al. (1993)

Host: Enteromius humilis (Boulenger) (Cypriniformes: Cyprinidae).

Site of infection: Body cavity.

Locality: Lake Tana near Bahir Dar, Ethiopia (collected 3 April 2006; ET016).

Prevalence and intensity: 9\% (1 fish infected/11 fish examined); 1 nematode.

Deposition of voucher specimen: IPCAS N-1123.

Remarks. The species identification of larvae of Contracaecum Railliet et Henry, 1912 from fishes, which serve as paratenic hosts (Moravec 2009), based on morphometrical features is practically impossible. A single specimen (ca $10 \mathrm{~mm}$ long) obtained from $B$. humilis belongs to the morphological group of Contracaecum larvae designated as Type 1 by Moravec et al. (1993), in which the ventricular appendage is longer than the intestinal caecum or both these are approximately equally long. The adult forms of these larvae are apparently fish-eating birds.

Contracaecum sp. third-stage larvae Type 2 of Moravec et al. (1993)

Hosts: Brycinus nurse (Rüppel) (Characiformes: Alestidae), Clarias gariepinus (Burchell), Clarias sp. (both Siluriformes: Clariidae) and Oreochromis niloticus (Linnaeus) (Perciformes: Cichlidae).

Site of infection: Body cavity.

L o c a lities: River Nile in Khartoum (Clarias sp.) (collected 28 March 2006; Sud183) and Atbara Dam Lake in Khashm el Girba (B. nurse) (25 November 2008; Sud502), both Sudan; Lake Tana near Bahir Dar, Ethiopia (C. gariepinus, O. niloticus) (6 April 2006; ET046, ET047).

Prevalence and intensity: $B$. nurse, Atbara Dam Lake: 1 fish infected/1 fish examined; 1 nematode. C. gariepinus, Lake Tana: 1/2, 1. Clarias sp., River Nile: $1 / 1,1$. O. niloticus Lake Tana: data not recorded (collected from several host specimens).

Deposition of voucher specimen: IPCAS N-468.

Remarks. The present Contracaecum specimens (body length about $10 \mathrm{~mm}$ from $B$. nurse and about $30-50 \mathrm{~mm}$ from $O$. niloticus; that from $C$. gariepinus not available) were collected from the above three host species and their morphology, in particular the presence of a very long caecum and a markedly short ventricular appendix, show that they belong to the Type 2 of Moravec et al. (1993). In Africa, similar larvae were reported, e.g. by Barson and Avenant-Oldewage (2006) from Clarias gariepinus and Moravec et al. (2016) from Sandelia capensis (Cuvier) in South Africa, and by Moravec and Van As (2015a) from six species of alestid, clariid and cichlid fishes in Botswana.

In many countries of Africa, larvae of Contracaecum have frequently been reported as parasites of many (cca 60) species of freshwater fishes belonging to different families and orders (e.g. Khalil and Polling 1997). In fact, they may belong to several species parasitising mainly fish-eating birds as adults.

Camallanoidea Railliet et Henry, 1915

Camallanidae Railliet et Henry, 1915

\section{Camallanus longicaudatus Moravec, 1973}

Description of female (one larvigerous specimen). Body length $19.8 \mathrm{~mm}$, maximum width 517. Buccal capsule including basal ring 150 long, maximum width 162; basal ring 21 long, 93 wide; length of tridents 144. Each valve of capsule with 19 ridges, 5 incomplete. Muscular oesophagus 639 long, 122 wide; glandular oesophagus 1,020 long, 60 wide; length ratio of both parts of oesoph- 
agus 1 : 1.6. Buccal capsule and oesophagus represent $9 \%$ of total body length. Nerve ring, excretory pore and deirids 313, 571 and 748, respectively, from anterior extremity. Vulva slightly postequatorial, $10.2 \mathrm{~mm}$ from anterior end of body at $51 \%$ of body length. Uterus extending posteriorly into tail, filled with numerous larvae. Tail very elongate, $2.6 \mathrm{~mm}$ long, representing $13 \%$ of body length, with rounded tip without any processes.

H o s t: Labeo niloticus (Linnaeus) (Cypriniformes: Cyprinidae). Site of infection: Intestine.

Locality: Nile River in Khartoum, Sudan (collected 23 March 2006; Sud038).

Prevalence and intensity: 1 fish infected/1 fish examined, 1 nematode.

Deposition of voucher specimen: IPCAS N-7.

Remarks. The only available female specimen was identified as C. longicaudatus, because its general morphology is more or less in agreement with the original description of this species (Moravec 1973). Although the female tail was only $2.6 \mathrm{~mm}$ long, as compared with 3.2-3.5 mm reported by Moravec (1973), its proportion to the body length was the same (13\% vs 12-14\%). The female tail of C. kirandensis Baylis, 1928 is only $1.4 \mathrm{~mm}$ long, representing $14 \%$ of the body length (Baylis 1928). Moreover, C. longicaudatus was described from the congeneric host Labeo horie Heckel of the River Nile in Cairo, Egypt.

Another morphologically similar species of Camallanus Railliet et Henry, 1915 in Africa is C. kirandensis, originally described from an unidentified fish reported as a "Tanganyika barbel" (? Barbus sp.) in Lake Tanganyika, Tanzania (Baylis 1928). In contrast to the majority of other congeneric species, $C$. kirandensis is reported to possess only three pairs of postanal papillae. This was confirmed by S. Prudhoe (then British Museum [Natural History]), who re-examined in detail the holotype of C. kirandensis (see Moravec 1973). Subsequently, Amin (1978) also reported only three pairs of postanal papillae in specimens collected from Labeo niloticus in the Nile River at Cairo, Egypt, considered by him to be $C$. kirandensis. However, due to a poor documentation provided, his data do not seem to be reliable. Without describing the specimens, C. kirandensis was previously also reported by Khalil (1973) from Labeo altivelis Peters in Rhodesia (present Zimbabwe).

Paracamallanus cyathopharynx (Baylis, 1923)

Syn. Paracamallanus senegalensis Vassiliadès, 1970

Hosts: Clarias gariepinus (Burchell) and Clarias sp. (Siluriformes: Clariidae).

Site of infection: Intestine.

L o c a liti e s: Lake Tana, Ethiopia (C. gariepinus) (collected 3 April 2006; ET003) and Blue Nile in Sennar, Sudan (Clarias sp.) (collected 22 November 2008; Sud412c).

Prevalence and intensity: C. gariepinus, Lake Tana: 1 fish infected/1 fish examined; 1 nematode. Clarias sp., Blue Nile: $1 / 1 ; 1$.

Deposition of voucher specimens: IPCAS N-12.
Remarks. Only a single gravid female of Paracamallanus cyathopharynx was obtained from each of the above-mentioned hosts in the two localities. Their morphology was in full agreement with the redescription of this nematode species by Moravec and Van As (2015b).

\section{Procamallanus (Procamallanus) laeviconchus (Wedl, 1861)}

\section{Syn. Cucullanus laeviconchus Wedl, 1861}

Host: Synodontis schall (Bloch et Schneider) (Siluriformes: Mochokidae).

Site of infection: Intestine.

Locality: River Nile in Khartoum, Sudan (collected 21 March 2006; Sud032).

Prevalence and intensity: 1 fish infected/2 fish examined; 7 nematodes.

Deposition of voucher specimens: IPCAS N-13.

Remarks. The morphology and measurements of the present specimens (both males and females) collected from the type host $(S$. schall) are in agreement with the redescriptions of this species provided by Moravec and Van As (2004, 2015c).

Procamallanus laeviconchus was originally described by Wedl (1861) from S. schall in Egypt. To date, this nematode has been recorded from ten different Synodontis spp. (Mochokidae), which may be considered its main definitive hosts, and from Schilbe intermedius (Schilbeidae) in Egypt, Sudan, Chad, Ghana, Nigeria, Benin, Botswana, Uganda and the Democratic Republic of the Congo (Moravec and Van As 2015c). According to Moravec and Van As (2004), P. laeviconchus has been reported from about 30 fish species belonging to seven families in many African countries, but apparently other species have been misidentified under this name (Campana-Rouget 1961, Moravec and Van As 2015c).

Recently, Moravec and Van As (2015c) erected a new species, P. pseudolaeviconchus Moravec et Van As, 2015, a parasite of Clarias spp. (Clariidae) in Africa, which was previously often misidentified as $P$. laeviconchus.

\section{Procamallanus (Spirocamallanus) pseudospiralis $\mathrm{sp} . \mathrm{n}$.}

Figs. 7, 8

ZooBank number for species:

urn:lsid:zoobank.org:act:B41F3097-E54A-4192-9837-6341C49DF96C

Description. Medium-sized nematode with finely transveresely striated cuticle. Mouth aperture oval, surrounded by 8 submedian cephalic papillae arranged in 2 circles, each formed by 4 papillae (papillae of external circle distinctly larger) (Fig. 7D,E); additional 6 small internal papillae (2 lateral and 4 submedian) present near margin of oral aperture; pair of small lateral amphids present. Orange-brown buccal capsule well sclerotised, barrel-shaped, distinctly longer than wide, with simple, well-developed basal ring. Inner surface of capsule provided with 8-11 (1-3 incomplete) spiral ridges in lateral view (Fig. 7A-E). Mus- 
cular oesophagus claviform, slightly shorter than glandular oesophagus. Glandular oesophagus somewhat expanded at its approximately $2 / 3$ of its length, followed by distinctly narrowed posteriormost portion; oesophagus opens into intestine through small valve (Fig. 7A-C). Intestine brown, narrow. Deirids small, simple, with rounded end situated slightly posterior to level of nerve ring (Fig. 7A-C). Excretory pore just anterior to level of posterior end of muscular oesophagus or, more frequently, somewhat posterior to level of anterior end of glandular oesophagus (Fig. 7A,B). Tail of both sexes conical, ending in sharp cuticular spike (Fig. 7F,G,I-K).

Male (two specimens from S. schall; holotype; measurements of paratype in parentheses). Length of body $17.6 \mathrm{~mm}$ (17.5 mm), maximum width 313 (313). Buccal capsule including basal ring 96 (87) long, its width 78 (66); basal ring 12 (12) long and 51 (48) wide. Maximum width/ length ratio of buccal capsule $1: 1.23$ (1: 1.32). Spiral ridges 9 (8), 1 (1) of which incomplete. Length of muscular oesophagus 476 (462), maximum width 93 (84); length of glandular oesophagus 530 (530), maximum width 90 (87); length ratio of muscular and glandular oesophagus $1: 1.11$ (1: 1.15). Length of entire oesophagus and buccal capsule represents $6 \%(6 \%)$ of body length. Nerve ring, deirids and excretory pore 313 (299), 598 (530) and 330 (348) from anterior extremity, respectively.

Posterior end of body ventrally bent, provided with wide, vesiculated caudal alae supported by pedunculate papillae; anteriorly alae interconnected by mound, forming thus a kind of pseudosucker, and posteriorly reaching nearly to caudal end (Fig. 7F,G). Preanal papillae: 3 pairs of subventral pedunculate papillae; postanal papillae: 6 pairs (last pair representing phasmids); additional 2 pairs of small transversely elongate sessile ventral papillae surrounding cloacal opening (Fig. 7F,G). Spicules similar in shape, unequal, with pointed distal ends; large (right) spicule 213 (225) long; small (left) spicule less sclerotised, 102 (153) long (Fig. 7F,G). Length ratio of spicules $1: 2.09$ (1 : 1.47). Gubernaculum absent. Tail conical, 255 (249) long, ending in sharp cuticular spike (Fig. 7F,G).

Female (five larvigerous specimens from $S$. schall; measurements of allotype in parentheses): Length of body 36.7-38.8 mm (37.9 mm), maximum width 762-870 (870). Buccal capsule including basal ring 96-102 (99) long and 75-84 (81) wide; basal ring 9-12 (12) long and 54-57 (54) wide. Maximum width/length ratio of buccal capsule 1 : 1.14-1.36 (1 : 1.22). Number of spiral ridges 9-11 (9), of which 1-3 (2) incomplete. Length of muscular oesophagus 530-625 (625), maximum width 95-109 (109); length of glandular oesophagus 694-843 (843), maximum width 95-109 (95); length ratio of muscular and glandular oesophagus $1: 1.17-1.35$ ( $1: 1.35)$. Length of entire oesophagus and buccal capsule representing 3-4\% (4\%) of body length. Nerve ring, deirids and excretory pore 340-367 (354), 544-571 (558) and 639-680 (639) from anterior extremity, respectively. Vulva pre-equatorial, 14.6-16.1 mm (15.4 mm) from anterior extremity, at $39-42 \%(41 \%)$ of body length. Vagina muscular, directed posteriorly from vulva (Fig. $7 \mathrm{H})$. Uterus filled with numerous larvae and eggs; cephalic end of larvae provided with 4 submedian papillae and pair of lateral amphids (Fig. 8A), whereas larval tail tip bears 5-6 digit-like processes 2-3 long (Fig. 8B-D). Female tail conical to rounded, abruptly narrowed to form distinct spike-like distal portion (Fig. 7I,K); entire tail 186-213 (192) long, length of narrowed portion 33-60 (48).

Type host: Synodontis schall (Bloch et Schneider) (Siluriformes: Mochokidae).

Other hosts: Synodontis frontosus Vaillant and S. nigrita Valenciennes (both Siluriformes: Mochokidae).

Site of infection: Intestine.

Type locality: River Nile in Khartoum, Sudan ( $S$. schall) (collected 21 March 2006; Sud023, Sud032).

Other locality: Atbara Dam Lake in Khashm el Girba, Sudan (S. frontosus, S. nigrita, S. schall) (collected 25-28 November 2008; Sud524, Sud536b, Sud558d, Sud558e, Sud589c).

Prevalence and intensity: S. schall, Nile River: 2 fish infected/2 fish examined; 7 and 12 nematodes per fish. S. frontosus, Atbara Dam Lake: 3/4; 1-6. S. nigrita, Atbara Dam Lake: $1 / 3 ;$ 6. S. schall, Atbara Dam Lake: $1 / 2 ; 6$.

Deposition of type (holotype, allotype and 2 paratypes) and voucher specimens: IPCAS $\mathrm{N}-1124$.

Etymology: The specific name pseudospiralis relates to the fact that until recently this species was confused with P. (S.) spiralis Baylis, 1923.

Remarks. To date, five species of Procamallanus (Spirocamallanus) Baylis, 1923 are known to parasitise inland fishes in Africa: P. (S.) daleneae (Boomker, 1993) mainly from Synodontis spp. in South Africa, Botswana and the Democratic Republic of the Congo, P. (S.) olseni (Campana-Rouget et Razarihelissoa, 1965), a parasite of marine perciform fishes, recorded from Rhabdosargus sarba (Forsskål) (Sparidae) in an inland brackish-water lake in South Africa, P. (S.) parachannae Moravec et Jirků, 2015 from Parachanna insignis (Sauvage) in the Democratic Republic of the Congo, $P$. (S.) serranochromis Moravec et Van As, 2015 from Serranochromis spp. (Boulenger) in Botswana, and P. (S.) spiralis mainly from Clarias spp. in Egypt, Sudan, Botswana and Zambia (Baylis 1923b, Khalil 1969, Boomker 1993, Gibbons and Saayman 1996, Moravec and Jirků 2015, Moravec and Van As 2015d).

The new species is most similar to $P$. $(S$.) spiralis (as redescribed by Moravec and Van As 2015d), from which it differs in having a distinctly shorter right spicule (213$225 \mu \mathrm{m} v s$ 399-473 $\mu \mathrm{m}$ ) and a much shorter glandular oesophagus relative to the muscular oesophagus (glandular oesophagus slightly longer vs glandular oesophagus conspicuously longer, i.e. the ratio of both parts $1: 1.1-1.4 \mathrm{vs} 1$ : 1.9-2.6). Moreover, only 8-11 (most frequently 10) spiral ridges were found in the buccal capsule of the new species, whereas usually 12 (rarely 11 or 10 ) spiral ridges are present in $P$. (S.) spiralis (see Yeh 1957, Moravec and Van As 2015d). The main differences of the new species from all of the above-mentioned African congeners are apparent from the following key. 

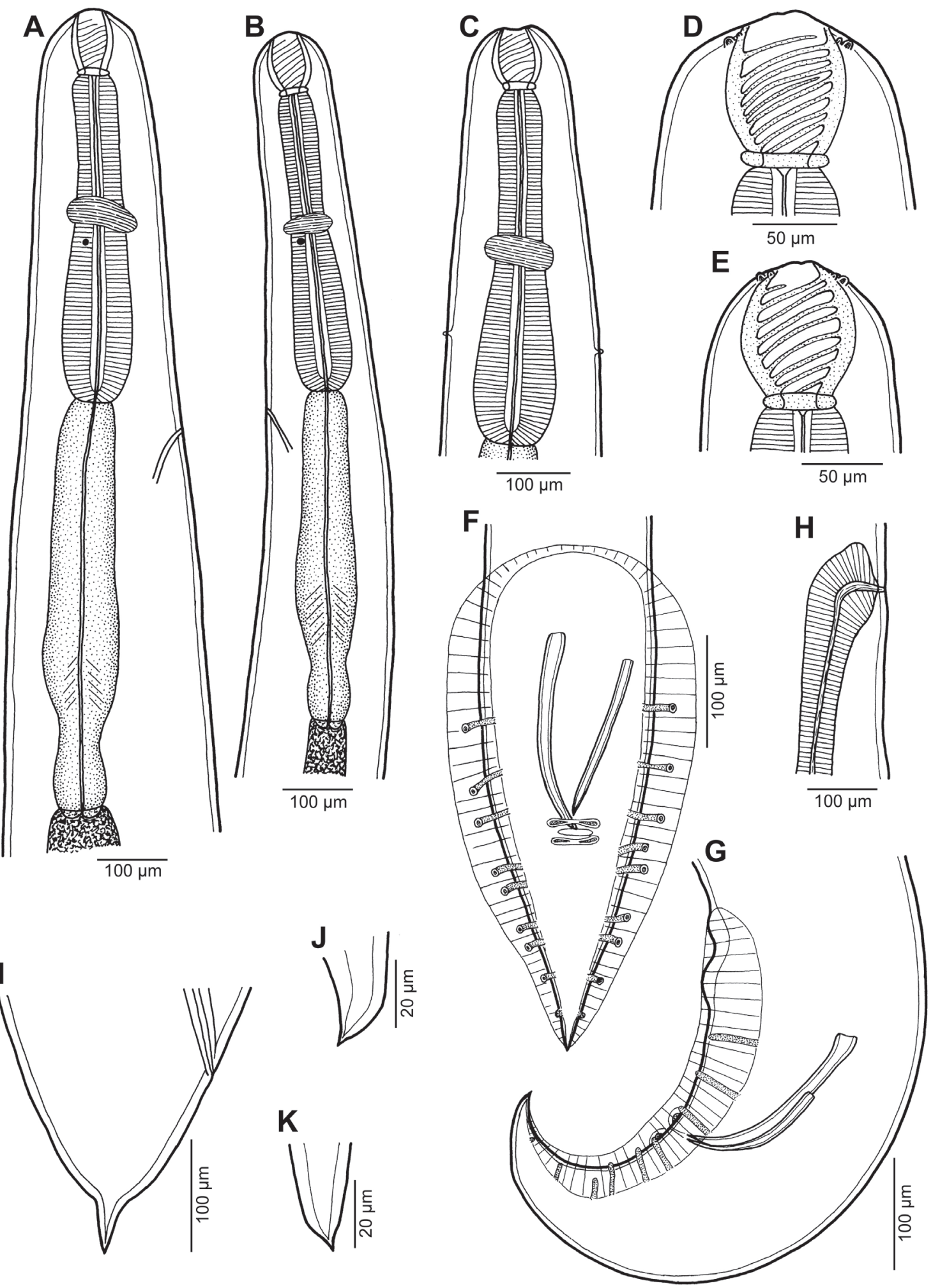

Fig. 7. Procamallanus (Spirocamallanus) pseudospiralis sp. n. from Synodontis schall (Bloch et Schneider). A, B - anterior part of body of gravid female and male, respectively, lateral views; $\mathbf{C}$ - anterior end of gravid female, dorsoventral view; $\mathbf{D}, \mathbf{E}$ - buccal capsule of gravid female and male, respectively, lateral views; $\mathbf{F}, \mathbf{G}$ - posterior end of male, ventral and lateral views, respectively; $\mathbf{H}$ - region of vulva, lateral view; I - tail of gravid female, lateral view; $\mathbf{J}, \mathbf{K}$ - tail tip of male and gravid female, respectively. 

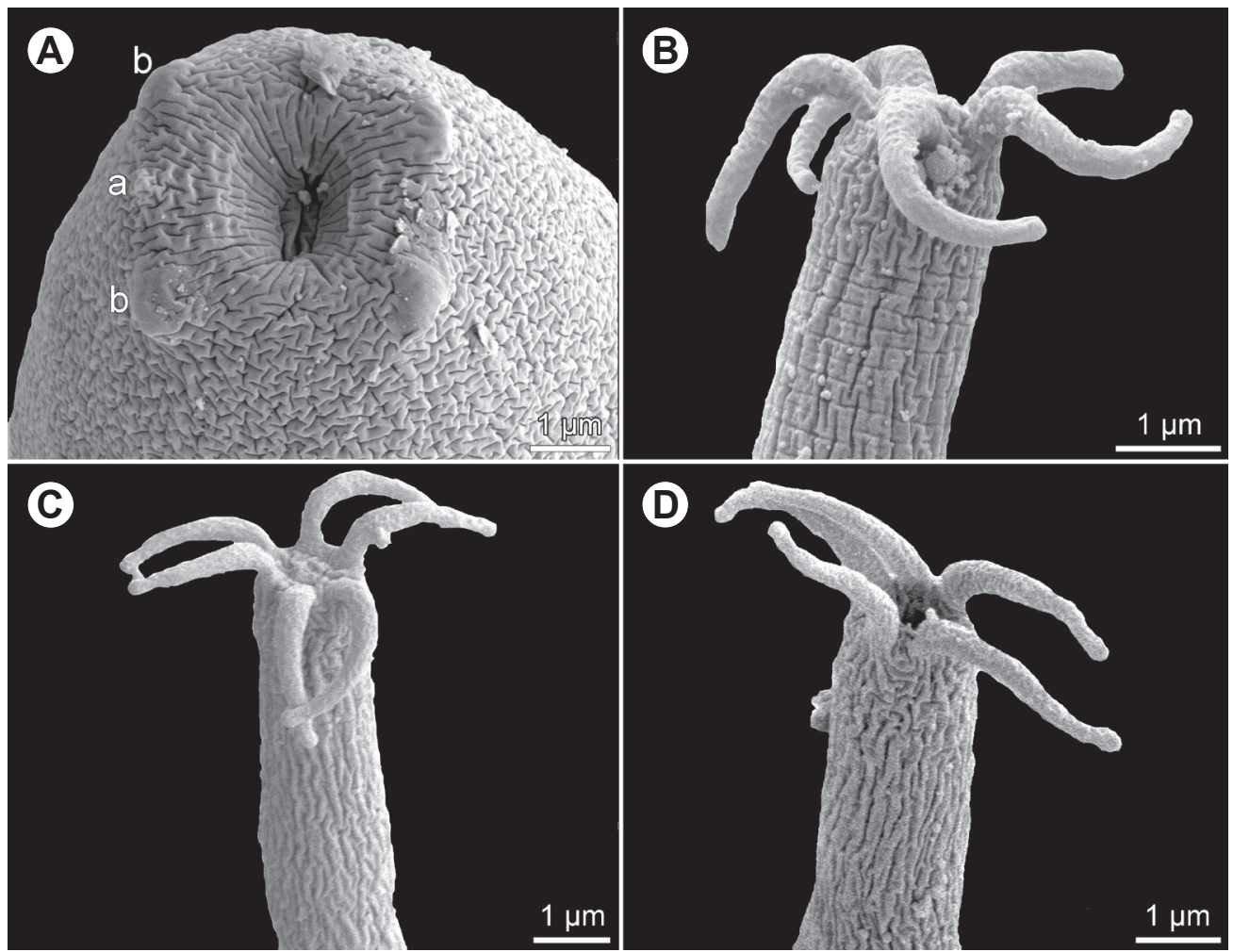

Fig. 8. Procamallanus (Spirocamallanus) pseudospiralis sp. n. from Synodontis schall (Bloch et Schneider), scanning electron micrographs of first-stage larva from uterus. A - cephalic end, apical view; B, D - tail tip of larvae with five digit-like processes; $\mathbf{C}$ - tail tip of larva with six digit-like processes. Abbreviations: a - amphid; b - cephalic papilla.

Key to Procamallanus (Spirocamallanus) spp. parasitic in freshwater fishes in Africa (one marine species recorded from an African brackish lake is also included)

1 Parasitic mainly in Siluriformes. Tail tip of both sexes without any projections 2

- Parasitic in Perciformes. Tail tip of both sexes with two minute projections or with blunt, slightly bilobed tip in male and rounded tip without terminal lobes in conspecific female

2 Large (right) spicule $>390 \mu \mathrm{m}$. Buccal capsule barrel-shaped, with 10-12 spiral ridges. Glandular oesophagus much longer than muscular oesophagus (length ratio of both portions $1: 1.9-2.6)$. Parasitic mainly in Clariidae (Clarias) ........................... P. (S.) spiralis

- Large (right) spicule $<250 \mu \mathrm{m}$ long. Glandular oesophagus approximately as long as muscular oesophagus (length ratio of both portions $1: 0.7-1.4$ ) .............. 3

3 Buccal capsule globosely funnel-shaped, with 13-17 spiral ridges. Posterior end of glandular oesophagus without constriction. Excretory pore at level of muscular oesophagus. Tail of gravid female conical, with short, abrumptly narrowed distal part; tip rounded. Parasitic in Mochokidae (some species of Synodontis) in South Africa, Botswana and the Democratic Republic of the Congo P. (S.) daleneae
- Buccal capsule barrel-shaped, with 8-11 spiral ridges. Posterior end of glandular oesophagus with conspicuous constriction. Excretory pore usually at level of anterior end of glandular oesophagus, rarely at level of posterior end of muscular oesophagus. Tail of gravid female conical, with short, abruptly narrowed distal part; tip sharply pointed. Parasitic in Mochokidae (Synodontis schall) in the Sudan and the Democratic Republic of the Congo ....... P. (S.) pseudospiralis sp. n.

4 Large (right) spicule $<330 \mu \mathrm{m}$ long. Excretory pore well posterior to posterior end of muscular oesophagus. Deirids slightly posterior to buccal capsule. Buccal capsule with 12-16 spiral ridges. Caudal outgrowths spike-like. Parasitic in marine fishes; recorded from Sparidae (Rhabdosargus) in an inland brackish-water lake in South Africa .............................. P. (S.) olseni

- Large (right) spicule $>420 \mu \mathrm{m}$. Excretory pore at level of muscular oesophagus. Deirids just anterior to nerve ring. Buccal capsule with 9-13 spiral ridges. Caudal outgrowths rounded ............................................... 5

5 Large spicule $546 \mu \mathrm{m}$ long. Buccal capsule with 10 spiral ridges. Parasitic in Channidae (Parachanna) in the Democratic Republic of the Congo

P. (S.) parachannae

- Large spicule 429-498 $\mu \mathrm{m}$ long. Buccal capsule with 9-13 spiral ridges. Parasitic in Cichlidae (Serranochromis) in Botswana $P$. (S.) serranochromis 
A remarkable finding is the presence of minute digit-like processes on the tail tip of the first-stage larvae of the new species. Based on SEM studies, similar caudal processes were described in the first-stage larvae of two species of Camallanus, C. cotti Fujita, 1927 from New Caledonia and C. lacustris (Zoega, 1776) from the Czech Republic (Moravec and Justine 2006) and later in the larvae of two species of Procamallanus, Procamallanus (P.) sp. [reported as $P$. (P.) laeviconchus] and $P$. (S.) pseudolaeviconchus Moravec et Van As, 2015 [reported as Procamallanus $(P$.) sp.] from Kenya (Mašová et al. 2011). Similar digit-like processes were also reported for four species of Procamallanus parasitising marine fishes from off New Caledonia and Thailand (Moravec and Justine 2011, Yooyen et al. 2011), but these larvae were not studied by SEM, so their minute caudal processes are not well visible in drawings. As pointed out by Moravec and Justine (2006), the number of such larval processes might be of taxonomic importance in camallanids. Whereas 5-6 caudal processes were observed in larvae of $P$. (S.) pseudospiralis of the present material, 9-11 and 14-15 processes were present in those of $P$. (P.) pseudolaeviconchus and Procamallanus (P.) sp., respectively, reported by Mašová et al. (2011).

Habronematoidea Chitwood et Wehr, 1932

Cystidicolidae Skryabin, 1946

Spinitectus polli Campana-Rouget, 1961

Syn. Spinitectus zambezensis Boomker, 1993

Description of female (one ovigerous specimen). Body length $5.6 \mathrm{~mm}$, maximum width 163. Cuticular spines as described by Moravec and Van As (2015b). Vestibule including prostom 87 long. Length of muscular oesophagus 189 , width 21; of glandular oesophagus 830 , width 75 ; length ratio of both oesophageal portions $1: 4.4$. Excretory pore situated at level of 4th ring of cuticular spines, 186 from anterior extremity. Nerve ring 171 from anterior end of body. Vulva situated $4.5 \mathrm{~mm}$ from anterior extremity, i.e. at $80 \%$ of entire body length. Uterus contains numerous larvated eggs 36-39 × 24-27 in size. Length of tail 57 .

Host: Synodontis schall (Bloch et Schneider) (Siluriformes: Mochokidae).

Site of infection: Intestine.

Locality: River Nile in Khartoum, Sudan (collected 21 March 2006; Sud032).

Prevalence and intensity: 1 fish infected/2 fish examined; 1 nematode.

Deposition of voucher specimen: IPCAS N-1081.

Remarks. The general morphology of the only available female specimen agrees well with the redescription of $S$. polli provided by Moravec and Van As (2015b); moreover, its host ( $S$. schall) is the type host of this nematode species.

Spinitectus polli was originally described by Campana-Rouget (1961) from S. schall in Lake Albert, the
Democratic Republic of the Congo; she also listed S. polli from Alestes dentex (Linnaeus) and Brycinus macrolepidotus Valenciennes (both Alestidae, Characiformes) in the same locality, but these findings need to be revised, because these hosts are representatives of a different fish order (Moravec and Van As 2015b). This nematode species (reported as $S$. zambezensis) was also recorded from Synodontis zambezensis Peters in South Africa (Boomker 1993, 1994, Boomker and Puylaert 1994) and from S. nigromaculatus Boulenger in Botswana (Moravec and Van As 2004, 2015b). The present finding of $S$. polli in the $\mathrm{Su}-$ dan represents a new geographical record.

Trichinelloidea Ward, 1907

Capillariidae Railliet, 1915

\section{Capillariidae gen. sp.}

Host: Auchenoglanis sp. (Siluriformes: Claroteidae).

Site of infection: Intestine.

L o c a lity: White Nile in Kostí, Sudan (collected 25 March 2006; Sud106).

Prevalence and intensity: 1 fish infected/1 fish examined; 1 nematode.

Deposition of voucher specimen: Not deposited.

Remarks. Only a single gravid female nematode was collected. However, without having a conspecific male, the generic identification of this specimen is impossible. To date, only one capillariid nominal species, Capillostrongyloides fritschi (Travassos, 1914), is known to occur in African freshwater fishes, being reported from the catfishes Malapterurus electricus (Gmelin), Bagrus bajad (Geoffroy Saint-Hilaire) and B. docmak (Forsskål) in Egypt and the Democratic Republic of the Congo (Moravec 2001). In addition, Boomker (1994) reported Capillaria (s. 1.) sp. from the catfishes Clarias gariepinus and Synodontis zambezensis in South Africa.

\section{Dioctophymatoidea Castellani et Chalmers, 1910}

Dioctophymatidae Castellani et Chalmers, 1910

Eustrongylides sp. fourth-stage larvae

Ho st: Enteromius humilis (Boulenger) (Cypriniformes: Cyprinidae).

Site of infection: Body cavity.

L o cality: Lake Tana near Bahir Dar, Ethiopia (collected 3 and 4 April 2006; ET011, ET018, ET019, ET020, ET021, ET022, ET023, ET024).

Prevalence and intensity: $8 \%$ (10 fish infected/122 fish examined); 1-5 (mean 2) nematodes per fish.

Deposition of voucher specimen: IPCAS N-76.

Remarks. The morphology of available specimens is identical with that reported by Moravec and Van As (2015a). Third- and fourth stage larvae of Eustrongylides Jägerskiöld, 1909 from fishes and some other aquatic vertebrates, serving as paratenic hosts, are unidentifiable to 
species by morphological and biometrical features. Adults of this genus are parasites of the proventriculus of fish-eating birds. Larvae of Eustrongylides are occasionally found as the parasites of humans after being ingested along with raw fish (Eberhard et al. 1989).

Larvae of species of Eustrongylides have already been reported from a variety of fish species in Africa, mainly those belonging to the family Cichlidae (e.g. Paperna 1974).

\section{DISCUSSION}

Although the history of studies on nematodes in African freshwater fishes dates back to the second half of the 19 th century, as mentioned above, the fauna of these parasites in Africa is still little known. The second edition of Check list of the helminth parasites of African freshwater fishes (Khalil and Polling 1997) can be considered a kind of milestone in these studies, that provides an inventory of nematode species, besides other helminths, recorded from Africa until the end of the last century.

During the first two decades of the 21 st century, many papers treating fish nematodes by researchers from some African countries, in particular those from Nigeria and Zimbabwe, were published, mostly oriented to the recognition of the local helminth fauna of fishes, with emphasis to some groups of fish hosts. However, reported nematodes remained mostly unidentified to species or, sometimes, their identification is questionable. Apparently, these problems are associated with an insufficient elaboration of the taxonomy of these parasites and hitherto fragmented data on their distribution in fishes of Africa.

In this period, several important papers dealing with African fish nematodes have been published, including descriptions of 15 new species of the Ascaridoidea (Dujardinascaris Baylis, 1947), Camallanoidea (Procamallanus Baylis, 1923), Cosmocercoidea (Orientatractis Petter, 1966), Dracunculoidea (Mexiconema Moravec, Vidal et
Salgado Maldonado, 1992, Philometra Costa, 1845 and Philometroides Yamaguti, 1935), Oxyuroidea (Cithariniella Khalil, 1964 and Synodontisia Petter, Vassiliadès et Troncy, 1972) and Thelazioidea (Rhabdochona Railliet, 1916), erection of two new genera (Afrophilometra Moravec, Charo-Karisa et Jirků, 2009 and Mexiconema) and redescriptions of many other insufficiently known species (e.g. Koubková et al. 2008, 2010, Moravec et al. 2009a,b, 2013, Moravec and Jirků 2014a,b, 2015, Moravec and Van As 2015a,b,c,d, González-Solís and Mariaux 2017). Erection of so many new nematode taxa within such a short period documents again that the composition of the fauna of African fish nematodes remains to be little known. Therefore, the present survey of fish nematodes in the Sudan and Ethiopia, so far little-explored regions in this respect, containing data on 16 species (including two new for science), represents an important contribution to the recognition of these parasites in Africa.

Acknowledgements. The authors' thanks are due to the staff of the Laboratory of Electron Microscopy, Institute of Parasitology, Biology Centre of the CAS, České Budějovice, for their technical assistance, and to Blanka Škoríková of the same Institute for help with the illustrations. The research stays of T. S. in the Sudan in 2006 and 2008 would not have been possible without the invaluable help of Zuheir N. Mahmoud, Ali Adam and Sayed Yousif Osman Elsheikh (University of Khartoum), Khalid Bashir Abaker and Ammar Osmar (White Nile Fisheries Research Station in Kostí) and in Ethiopia in 2008 without the support and advice of Abebe Getahun Gubale and Seyoum Mengistou, and Moges Beletew, Department of Biology, Faculty of Science, Addis Ababa University, and Eshete Dejen Dresilign, Director of Fisheries \& Livestock Branch, Amhara Regional Agricultural Research Institute, Bahir Dar. Thanks are also due to Alain de Chambrier for help with dissecting fishes. This study was supported by the Czech Science Foundation (Grant. No. P505/12G112) and by institutional support (RVO: 60077344, Institute of Parasitology, BC CAS).

\section{REFERENCES}

Abdel-Ghaffar F., Bashar A.-R., Abdel-Gaber R., Morsy K., Mehlhorn H., Al Quraishy S., Mohammed S. 2014: Cucullanus egyptae sp. nov. (Nematoda, Cucullanidae) infecting the European eel Anguilla anguilla in Egypt. Morphological and molecular phylogenetic study. Parasitol. Res. 113: 3457-3465.

Akinsanya B., Hassan A.A., Otubanjo O.A. 2007: A comparative study of the parasitic helminth fauna of Gymnarchus niloticus (Gymnarchidae) and Heterotis niloticus (Osteoglossidae) from Lekki Lagoon, Lagos, Nigeria. Pakistan J. Biol. Sci. 10: 427-432.

Aкram M. 1994: Studies on host parasite relationships between marine food fishes of Sindh creeks and cucullanid nematode parasites (Cucullanidae: Nematoda) in Pakistan. Pakistan J. Zool. 26: $182-185$.

Amin O.M. 1978: Intestinal helminths of some Nile fishes near Cairo, Egypt with redescriptions of Camallanus kirandensis Baylis 1928 (Nematoda) and Bothriocephalus aegyptiacus Ryšavý and

1975 (Cestoda). J. Parasitol. 64: 93-101.

Barson M., Avenant-Oldewage A. 2006: Nematode parasites of Clarias gariepinus (Burchell, 1822) from the Rietvlei Dam, South Africa. Onderstepoort J. Vet. Res. 73: 87-94.
BAylis H.A. 1923a: Some nematodes of the genus Cucullanus from fishes of the Nile. Ann. Mag. Nat. Hist., Ser. 9, 12: 233-236.

BAylis H.A. 1923b: Report on a collection of parasitic nematodes, mainly from Egypt. Parasitology 15: 24-38.

BAylis H.A. 1928: Some parasitic worms, mainly from fishes, from Lake Tanganyika. Ann. Mag. Nat. Hist., Ser. 9, 12: 233-236.

Bharata Lakshmi B. 2000: A new parasite of the genus Cucullanus (Nematoda: Cucullanidae) from the fish Arius thalassinus (Ruppel). Bol. Chil. Parasitol. 55: 3-4.

Bharatalakshmi B., Sudha M. 2000: On a new species of the genus Cucullanus Mueller, 1777 from the intestine of Arius thalassimus from Bheemili (Gosthani estuary). Riv. Parassitol. 17: 25-32.

Boomker J. 1993: Parasites of South African freshwater fish. IV. Description of Spirocamallanus daleneae n. sp. (Nematoda: Camallanidae) from Synodontis zambezensis Peters, 1852 (Mochokidae) with comments on Spirocamallanus spiralis (Baylis, 1923). Onderstepoort J. Vet. Res. 60: 131-137.

Boomker J. 1994: Parasites of South African freshwater fishes. VI. Nematode parasites of some fish species in the Kruger National Park. Onderstepoort J. Vet. Res. 61: 35-43. 
Boomker J., Puylaert F.A. 1994: Eight new Afrotropical Spinitectus spp. (Nematoda: Cystidicolidae) from freshwater fishes with a key to the members of the genus in the region. Onderstepoort J. Vet. Res. 61: 127-142.

Campana-Rouget Y. 1961: Nématodes de poissons. Exploration hydrobiologique des lacs Kivu, Édouard et Albert (1952-1954), Résultats Scientifiques, Bruxelles, 3: 1-61.

Černotíková E., Horák A., Moravec F. 2011: Phylogenetic relationships of some spirurine nematodes (Nematoda: Chromadorea: Rhabditida: Spirurina) parasitic in fishes inferred from SSU rRNA gene sequences. Folia Parasitol. 58: 135-148.

de Chambrier A., Scholz T., Beletew M., Mahmoud Z.N 2007: Redescription of Proteocephalus sulcatus (Klaptocz, 1906) (Cestoda: Proteocephalidea), a poorly known parasite of Clarotes laticeps (Pisces: Siluriformes) in Africa. Rev. Suisse Zool. 114: 693-702.

de Chambrier A., Sène A., Mahmoud Z., Mariaux J., Scholz T. 2008: Sandonella sandoni (Lynsdale, 1960), an enigmatic and morphologically unique cestode parasitic in the osteoglossiform fish Heterotis niloticus in Africa. J. Parasitol. 94: 202-211.

Eberhard M.L., Hurwitz H., Sun A.M., Coletta D. 1989: Intestinal perforation caused by larval Eustrongylides (Nematoda: Dioctophymatoidae) in New Jersey. Am. J. Trop. Med. Hyg. 40: 648-650.

El-Naffar M.K., Saoud M.F., Hassan I.M. 1983: A general survey of helminth parasites of some fishes of Lake Nasser at Aswan, A. R. Egypt. Assiut Vet. Med. J. 11: 141-183.

Froese R., Pauly D. (Eds.) 2017: FishBase. World Wide Web electronic publication, http://www.fishbase.org, 01/2017.

Gibbons L.M., SaAyman J.E. 1996: Redescription of Dichelyne (Dichelyne) rasheedae Petter, 1974 and Spirocamallanus olsen Campana-Rouget \& Razarihelissoa, 1965, recorded for the first time from fish in Lake St. Lucia, South Africa. Onderstepoort J. Vet. Res. 63: 39-46.

González-Solís D., Mariaux J. 2017: Orientatractis brycini sp. nov. (Nematoda: Atractidae) from characiform freshwater fishes in Gabon, Africa. Rev. Suisse Zool. 124: 1-8.

KhaLIL L.F. 1962: On two new nematodes from freshwater fishes in the Sudan of the genus Spironoura Leidy, 1856 and the relation of Spironoura to the genus Velariocephalus Singh, 1958. J. Helminthol. 36: 51-58.

KhaliL L.F. 1969: Studies on the helminth parasites of freshwater fishes of the Sudan. J. Zool., London, 158: 143-170.

KhaLIL L.F. 1971: Check List of the Helminth Parasites of African Freshwater Fishes. Commonwealth Agricult. Bureaux, Slough, $80 \mathrm{pp}$.

KHALIL L.F. 1973: Some nematodes from freshwater fishes of Rhodesia with description of a new species Cithariniella petterae $\mathrm{n}$. sp. Ann. Parasitol. Hum. Comp. 48: 811-818.

Khalil L.F., Polling L. 1997: Check List of the Helminth Parasites of African Freshwater Fishes. Second Edition. University of the North, Pietersburg, $185 \mathrm{pp}$.

KoubKová B., Baruš V., Hodová I. 2010: Nematodes of Cithariniella (Pharyngodonidae) from freshwater fishes in Senegal, with a key to species. Helminthologia 47: 105-114.

Koubková B., Baruš V., Hodová I., Šimková A. 2008: Morphometric and molecular characteristics of Labeonema synodontisi n. comb. (Nematoda: Atractidae) from the West African fishes. Parasitol. Res. 102: 1013-1020.

Kuchta R., Burianová A., JirkŮ M., De Chambrier A., Oros M., Brabec J., Scholz T. 2012: Bothriocephalidean tapeworms (Cestoda) of freshwater fish in Africa, including erection of Kirstenella n. gen. and description of Tetracampos martinae n. sp. Zootaxa 3309: 1-35.

Lévêque C., Oberdorff T., Paugy D., Stiassny M.L.J., TeDESCO P.A. 2008: Global diversity of fish (Pisces) in freshwater Hydrobiologia 595: 545-567.

Mašová Š., Baruš V., MoraVec F. 2011: New morphological data on the first-stage larvae of two Procamallanus species (Nema- toda: Camallanidae) based on SEM studies. Folia Parasitol. 58: 318-321.

Mašová Š., Moravec F., Baruš V., Seifertová M. 2010: Redescription, systematic status and molecular characterisation of Multicaecum heterotis Petter, Vassiliadès et Marchand, 1979 (Nematoda: Heterocheilidae), an intestinal parasite of Heterotis niloticus (Osteichthyes: Arapaimidae) in Africa. Folia Parasitol. 57: $280-288$.

Moravec F. 1973: On the nematode Camallanus longicaudatus sp. n. from the Nile fish, Labeo horie Heck. (Vermes). Rev. Zool. Bot. Afr. 87: 165-173.

Moravec F. 1974: On some nematodes from Egyptian freshwater fishes. Acta Soc. Zool. Bohemoslov. 38: 32-51.

Moravec F. 2001: Trichinelloid Nematodes Parasitic in Cold-Blooded Vertebrates. Academia, Prague, 429 pp.

Moravec F. 2009: Experimental studies on the development of Contracaecum rudolphii (Nematoda: Anisakidae) in copepod and fish paratenic hosts. Folia Parasitol. 56: 185-193.

Moravec F., Charo-Karisa H., Jirků M. 2009a: Philometrids (Nematoda: Philometridae) from fishes of Lake Turkana, Kenya, including two new species of Philometra and erection of Afrophilometra gen. n. Folia Parasitol. 56: 41-54.

Moravec F., Charo-Karisa H., Jirků M. 2013: The morphology and systematic status of Rhabdochona paski Baylis, 1928 (Nematoda: Rhabdochonidae), a widespread parasite of freshwater fishes in Africa. Syst. Parasitol. 85: 55-63.

Moravec F., Charo-Karisa H., JirkŮ M., Mašová Š. 2009b: Mexiconema africanum sp. n. (Nematoda: Daniconematidae) from the catfish Auchenoglanis occidentalis from Lake Turkana, Kenya. Parasitol. Res. 105: 1047-1052.

Moravec F., Jansen van Rensburg C., Van As L.L. 2016: Larvae of Contracaecum sp. (Nematoda: Anisakidae) in the threatened freshwater fish Sandelia capensis (Anabantidae) in South Africa. Dis. Aquat. Org. 120: 251-254.

MoRAVEC F., JiR KU M. 2014a: Dujardinascaris mormyropsis n. sp. (Nematoda: Anisakidae) from the osteoglossiform fish Mormyrops anguilloides (Linnaeus) (Mormyridae) in Central Africa. Syst. Parasitol. 88: 55-62.

MoraveC F., JirkŮ M. 2014b: Rhabdochona spp. (Nematoda: Rhabdochonidae) from fishes in the Central African Republic, including three new species. Folia Parasitol. 61: 157-172.

Moravec F., JirkU゚ M. 2015: Two Procamallanus (Spirocamallanus) species (Nematoda: Camallanidae) from freshwater fishes in the Lower Congo River. Acta Parasitol. 60: 226-233.

Moravec F., Justine J.-L. 2006: Camallanus cotti (Nematoda: Camallanidae), an introduced parasite of fishes in New Caledonia. Folia Parasitol. 53: 287-296.

Moravec F., Justine J.-L. 2011: New data on the morphology of Procamallanus (Procamallanus) annulatus and Procamallanus (Spirocamallanus) monotaxis (Nematoda: Camallanidae) from marine fishes off New Caledonia. Helminthologia 48: 41-50.

Moravec F., Kohn A., Fernandes B.M.M. 1993: Nematode parasites of fishes of the Paraná River, Brazil. Part 2. Seuratoidea, Ascaridoidea, Habronematoidea and Acuarioidea. Folia Parasitol. 40: 115-134.

Moravec F., Van As J.G. 2004: Nematodes from the squeaker fishes Synodontis nigromaculatus and $S$. vanderwaali from the Okavango River, Botswana, including three new species. Syst. Parasitol. 59: 169-187.

Moravec F., Van As L.L. 2015a: Studies on ascaridid, oxyurid and enoplid nematodes (Nematoda) from fishes of the Okavango River, Botswana. Folia Parasitol. 62: 039.

Moravec F., Van As L.L. 2015b: Studies on some spirurids (Nematoda: Spirurida) from fishes of the Okavango River, Botswana. Syst. Parasitol. 91: 119-138.

Moravec F., Van As L.L. 2015c: Procamallanus (Procamallanus) spp. (Nematoda: Camallanidae) in fishes of the Okavango River, Botswana, including the description of $P$. $(P$.) pseudolaeviconchus n. sp. parasitic in Clarias spp. (Clariidae) from Botswana and Egypt. Syst. Parasitol. 90: 137-149. 
Moravec F., VAn As L.L. 2015d: Procamallanus (Spirocamallanus) spp. (Nematoda: Camallanidae) from fishes of the Okavango River, Botswana, including $P$. (S.) serranochromis n. sp. parasitic in Serranochromis spp. (Cichlidae). Syst. Parasitol. 90 $151-164$.

Ndew D.E., Diouf M., BÂ C.T., Morand S. 2014: A new species of Cucullanus (Nematoda: Cucullaninae, Cucullanidae) from Mugil curema (Mugilidae) in Senegal (West Africa). Comp. Parasitol. 81: 15-22.

PAPERNA I. 1974: Hosts, distribution and pathology of infections with larvae of Eustrongylides (Dioctophymidae, Nematoda) in fishes from East African lakes. J. Fish Biol. 6: 67-76.

PARukhin A.M. 1989: [Parasitic Worms of Benthic Fishes of the Southern Seas.] Naukova Dumka, Kiev, 154 pp. (In Russian.)

Petter A.-J., Sey O. 1997: Nematode parasites of marine fishes from Kuwait, with a description of Cucullanus trachinoti n. sp. from Trachinotus blochi. Zoosystema 19: 35-59.
Petter A.-J., Vassiliadès G., Marchand B. 1979: Une nouvelle espèce de Multicaecum (Ascarididae, Nematoda) parasite de poisson en Afrique. Bull. Inst. Fond. Afr. Noire 41: 324-329.

VASSILIAdÈs G. 1973: Nématodes parasites de Distichodus rostratus Poisson Cithariniidae du lac de Guiers (Sénégal). Ann. Parasitol. Hum. Comp. 48: 469-475.

WEDL K. 1861: Zur Helminthenfauna Ägyptens. 2. Abtheilung, III. Nematoda. Sitzungsber. Kaiser. Akad. Wissensch., Math.-Nat. Cl., Wien, 44: 463-482 + Taf. I-III.

YeH L.S. 1957: On a nematode Spirocamallanus mazabukae sp. n. from freshwater fish in southern Africa. J. Helminthol. 31: $126-130$.

Yooyen T., Moravec F., Wongsawad C. 2011: Two new sibling species of Procamallanus (Spirocamallanus) (Nematoda: Camallanidae) from marine fishes in the Gulf of Thailand. J. Parasitol. 97: 931-938.

Cite this article as: Moravec F., Scholz T. 2017: Some nematodes, including two new species, from freshwater fishes in the Sudan and Ethiopia. Folia Parasitol. 64: 010. 